This PDF is a selection from a published volume from the National Bureau of Economic Research

Volume Title: The Economic Consequences of Demographic Change in East Asia, NBER-EASE Volume 19

Volume Author/Editor: Takatoshi Ito and Andrew Rose, editors

Volume Publisher: University of Chicago Press

Volume ISBN: 0-226-38685-6

ISBN13: 978-0-226-38685-0

Volume URL: http://www.nber.org/books/ito_08-2

Conference Date: June 19-21, 2008

Publication Date: August 2010

Chapter Title: Intergenerational Transfers and Old-Age Security in Korea Chapter Authors: Hisam Kim

Chapter URL: http://www.nber.org/chapters/c8163

Chapter pages in book: (227 - 278) 


\title{
Intergenerational Transfers and Old-Age Security in Korea
}

\author{
Hisam Kim
}

\subsection{Introduction}

Korea entered an aging society as of 2000, when people over age sixty-five made up 7.2 percent of the population. The ratio of the elderly population in Korea is projected to reach 14.3 percent by 2018 before it becomes a superaged society in 2026, with the share reaching 20.8 percent. Consequently, the elderly dependency ratio, which is defined as people aged sixty-five and over per people aged fifteen to sixty-four years, is projected to increase three times from 12.6 percent in 2005 to 37.7 percent in 2030, according to the Korea National Statistical Office.

In spite of its population aging at an unprecedented pace in the world, Korea has been unsuccessful in building up a social safety net for the elderly. Instead, adult children (mostly eldest sons) have undertaken the responsibilities of supporting their elderly parents in Korea's extended family. For this reason, empirical analysis of the financial support given to elderly parents by adult children is important in preparing an income guarantee policy that suits the current trend of the population aging and its subsequent social and economic changes.

Even though a substantial portion of Korean elderly have been living on financial assistance received from their children, studies on intergenerational transfers in Korea are rare and microeconomic empirical studies are even rarer. Part of the reason for this is there had been few microdata on intergenerational transfers until the twenty-first century. Now we have such data from at least three data sets: the Korean Labor and Income Panel Study (KLIPS), the Korean Longitudinal Study of Aging (KLoSA), and the

Hisam Kim is an associate fellow of the Korea Development Institute. 
Korean Retirement and Income Study (KReIS). This study examines microeconomic behavior on intergenerational transfers using these data sets.

First of all, this study directly looks into variables regarding intergenerational transfers in the three Korean data sets and compares them with those in the Health and Retirement Study (HRS), one of the elderly panel data sets that the KLoSA and the KReIS have tried to benchmark. Compared with the author's previous paper (Kim 2006) that uses data from the KLIPS, this study has both similarity and complementarity. The previous study analyzes a broad range of issues on private transfers - such as the magnitude and frequency of transfers, the determinants of transfer receipts and gifts, the crowding out of private transfers by public transfers, and the dead zones and loopholes of public assistance - and, therefore, some issues certainly overlap with this study. If we find similar results regarding the patterns and motivations of intergenerational transfers from these different data sets, we may get closer to stylized facts with the findings. Therefore, I cite or mention selected results from the previous study in some places of this chapter.

At the same time, however, this study deals with some unexplored issues using new features of the KLoSA and the KReIS data. First, the KLoSA respondents report their transfer receipts and gifts with all adult children who do not live with them. This resultant sibling sample motivates family fixed-effect models to examine which child gives more transfers to elderly parents or lives with them.

Second, the KReIS data report intergenerational transfers between parents and coresident children as well as between parents and noncoresident children. Considering that intergenerational transfers are reported only for noncoresident adult children in other data sets, we can have an unusual opportunity to examine intergenerational transfers by children's coresidence status and conjecture the motivations of those transfers.

Third, the KReIS survey has explicit questions on the existence of grandchildren who respondents and/or spouses are taking care of, the hours of caregiving, and the magnitude of pecuniary compensation, if any. These data items enable us to directly test whether there exists an exchange motive in adult children's cash transfers to their parents who look after grandchildren.

Fourth, the KLoSA survey asks about the respondents' subjective expectation feelings to several issues: for instance, the financial situation in their future, the relative financial situation of their children's generation compared to their own generation, and potential support for their old age by government. I use these variables to examine how individuals' expectations on tomorrow's situations affect their transfer behavior today.

Finally, the KLoSA and the KReIS data contain information on inheritances and detailed items of assets and debts. Using these variables that have rarely been observed in other data sets, this study first documents some basic statistics on inheritance and wealth in Korea. 
This chapter proceeds as follows. Section 7.2 quantifies intergenerational transfers focusing on adult children's transfers given to their elderly parents. Section 7.3 examines the characteristics of the donor and the recipient of such transfers to uncover which parents benefit more from their children and which child in the family gives more to the parents. Section 7.4 documents ongoing changes in familial support mechanism and suggests policy implications for old-age income security, based on observed profiles of income and wealth by age and by income quintile. The last section concludes.

\subsection{Patterns of Intergenerational Transfers}

In this section, I tabulate descriptive statistics on intergenerational transfers in Korea, and then those in the United States as well, for a cross-country comparison. First, I examine "inter-vivos" transfers; that is, transfers made while both the donor and the recipient are alive. Then, I look at reported and expected inheritance as another way that intergenerational transfers are made.

\subsubsection{Inter-Vivos Transfers}

First, I describe inter-vivos transfers in Korea, observed in the KLoSA, the KLIPS, and KReIS data sets focusing on adult children's financial help given to their elderly parents. The HRS data show striking differences in intergenerational transfer patterns between the United States and Korea.

\section{KLoSA Data}

The Korean Longitudinal Study of Aging (KLoSA) started in 2006 for the purpose of creating a basic data set needed to devise and implement effective policies to population aging. ${ }^{1}$ The KLoSA survey interviews middle/oldaged population (aged forty-five or older) nationwide, excluding Jeju Island. The total number of samples is 10,254 in 2006. Topics under KLoSA are grouped into the following seven main categories: (a) Demographics; (b) Family; (c) Health; (d) Employment; (e) Income; (f) Assets; (g) Subjective Expectations and Satisfaction. ${ }^{2}$

Specifically, rich information on intergenerational transfers in the Family section is extremely useful for this study. In the $2006 \mathrm{KLoSA}$ data, financial transfers between the respondent and each child during the last calendar year (2005) are asked if the child does not live with the respondent. According to the KLoSA questionnaire, financial help (or transfer) means giving

1. Basic survey for KLoSA will be conducted every even-numbered year starting from 2006, mostly using the same survey categories. The first KLoSA baseline survey was conducted over a six-month period from July 2006. The surveys thereafter will also be held in the second half of the year.

2. The data and questionnaires of the $2006 \mathrm{KLoSA}$ are available online at the website of Korea Labor Institute (www.kli.re.kr). 
money, helping pay bills, or covering specific types of costs (such as those for medical care or insurance, schooling, down payment for a home, rent, etc.), but it does not count any shared housing or shared food. Respondents are told that financial help can be considered as either a gift or a loan. The survey separately reports transfers made on a regular basis and those made irregularly. Regular monetary transfer refers to the case in which respondents received monetary transfers regularly in a certain time interval (e.g., each month, every two months), such as monthly allowances. Occasional (or irregular) monetary transfer refers to the case in which respondents received monetary transfers without any regularity, such as paying for medical bills or schooling and occasional allowances. I calculate annual regular transfer amount by multiplying the average amount of regular transfer by the number of months such transfer is made.

Intergenerational transfers in the KLoSA survey are reported not only for survey respondents and their children but also for the respondents and their own parents. The later generation data on the respondents and their children will be used in the main analyses of this study. The average age of parents (i.e., respondents) is 69.5 , and that of their children is 41.5 . In the earlier generation data on the respondents and their parents, the average age of respondents who have at least one living parent is 52.3, and their fathers and mothers are, on average, 79.1 and 78.8 years old, respectively. ${ }^{3}$ I add up financial assistance given to and received from the father and the mother if they are both alive. We have observations on intergenerational transfers made in 6,496 families for the later generation and those made in 3,159 families for the earlier generation.

Table 7.1 reports descriptive statistics on annual intergenerational transfers for each generation. Forty percent of respondents received financial transfers from their children and 11.4 percent gave financial help to their children. Average receipt amount is 1,040,000 won and average gift amount is 850,000 won, which yields average net transfer receipt of 190,000 won (surplus) for parents.

Looking at the earlier generation, 41.5 percent of respondents gave financial help to their elderly parents and 6 percent received financial support from them. Mean amount (both conditional and unconditional one) of net transfer is larger - more than double - for the earlier generation than for the later generation. Note that the former measures average net transfer received only from respondents, excluding those from their siblings, but the latter measures average net transfer received from all children of the respondents. Taking this different survey structure into account, the smaller amount of average net transfer receipt for the parents in the later generation may reflect a weakening role of children's financial support for their old parents. Other-

3. Given that at least one parent is alive, the fraction of the father's being alive is 0.323 and that of the mother's is 0.932 . 
Table 7.1

Annual intergenerational transfers in Korea: KLoSA data

$(\%, 10,000$ won $)$

\begin{tabular}{|c|c|c|c|c|c|}
\hline & & \multirow{2}{*}{$\begin{array}{c}\text { Fraction } \\
(\%)\end{array}$} & \multirow{2}{*}{$\begin{array}{l}\text { Unconditional } \\
\text { mean }\end{array}$} & \multicolumn{2}{|c|}{$\begin{array}{l}\text { Conditional } \\
\text { on making } \\
\text { each transfer }\end{array}$} \\
\hline & & & & Mean & Median \\
\hline \multicolumn{6}{|c|}{ Later generation (6,496 families) } \\
\hline \multirow[t]{3}{*}{ From children (A) } & Regular & 10.6 & 65 & 615 & 360 \\
\hline & Irregular & 35.3 & 39 & 111 & 60 \\
\hline & Total $^{\mathrm{a}}$ & 40.1 & 104 & 260 & 100 \\
\hline \multirow[t]{3}{*}{ To children (B) } & Regular & 5.0 & 54 & 1,079 & 720 \\
\hline & Irregular & 7.4 & 31 & 419 & 50 \\
\hline & Total $^{\mathrm{a}}$ & 11.4 & 85 & 749 & 315 \\
\hline \multirow{3}{*}{$\begin{array}{l}\text { Net transfer receipt } \\
\text { from children }(\mathrm{A}-\mathrm{B})\end{array}$} & Regular $^{\mathrm{b}}$ & 15.1 & 11 & 71 & 240 \\
\hline & Irregular ${ }^{\mathrm{b}}$ & 38.9 & 8 & 21 & 50 \\
\hline & Total $^{\mathrm{b}}$ & 46.3 & 19 & 41 & 70 \\
\hline \multicolumn{6}{|c|}{ Earlier generation (3,159 families) } \\
\hline \multirow[t]{3}{*}{ To parents $(\mathrm{C})$} & Regular & 10.2 & 42 & 413 & 240 \\
\hline & Irregular & 31.7 & 19 & 59 & 40 \\
\hline & Total $^{\mathrm{a}}$ & 41.5 & 61 & 147 & 50 \\
\hline \multirow[t]{2}{*}{ From parents (D) } & Regular & 0.7 & 1 & 82 & 12 \\
\hline & Irregular & 5.4 & 14 & 267 & 30 \\
\hline & Total $^{\mathrm{a}}$ & 6.1 & 15 & 247 & 30 \\
\hline \multirow{3}{*}{$\begin{array}{l}\text { Net transfer gift to } \\
\text { parents }(C-D)\end{array}$} & Regular $^{\mathrm{c}}$ & 10.8 & 41 & 383 & 234 \\
\hline & Irregular $^{\mathrm{c}}$ & 35.6 & 4 & 12 & 30 \\
\hline & Total $^{\mathrm{c}}$ & 45.8 & 46 & 100 & 50 \\
\hline
\end{tabular}

Source: Calculated by the author, using the 2006 KLoSA data.

Note: All numbers are calculated using weights assigned to family respondents.

${ }^{a}$ Either regular or irregular, or both transfers are made.

${ }^{b}$ Either from or to children, or both, some transfers are made.

${ }^{\mathrm{c}}$ Either to or from parents, or both, some transfers are made.

wise, it may reflect that the relative financial situation of parents to their children in the later generation is better than that in the earlier generation. Or, instead, it may simply reflect age difference between the parents in the two generations. At least the last conjecture seems to be supported by table 7.2. Net transfer receipt from children increases with the respondents' age from their fifties to early seventies. As parents get older, they are more likely to receive a large net transfer. ${ }^{4}$

4. Another possibility is a measurement error. In particular, we might need to account for potential underreporting bias when the respondents are asked to report their transfer receipts as opposed to their transfer gifts (see Gale and Scholz [1994] and Brown and Weisbenner [2002] for this bias). If KLoSA respondents indeed underreported transfers from their children (A) and/or from their parents (D), net transfer receipt from their children (A-B) should be underestimated and/or net transfer gift to their parents (C-D) should be overestimated in table 7.1. 
Mean amount of annual intergenerational transfer in Korea by age: KLoSA data $(10,000$ won)

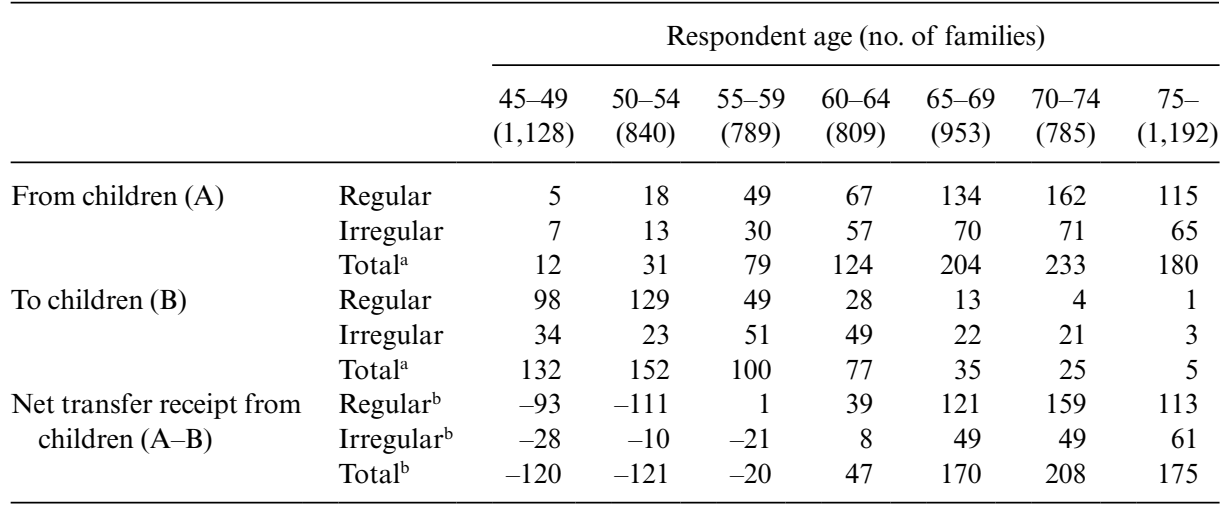

Source: Calculated by the author, using the 2006 KLoSA data.

Note: All numbers are calculated using weights assigned to family respondents.

${ }^{a}$ Either regular or irregular, or both transfers are made.

${ }^{b}$ Either from or to children, or both, some transfers are made.

In addition, table 7.2 shows that the direction of the net flow of intergenerational transfers is reversed from downward to upward around the parent's age sixty, a common retirement age. Transfer receipt from children increases as respondents get older, peaking at their mid-seventies, while transfer gift to children decreases after their fifties. Although these profiles are constructed from cross-section data, they probably depict a life cycle reallocation through intergenerational transfers within Korean families.

\section{KLIPS Data}

The Korean Labor and Income Panel Study (KLIPS) is an annual survey of 5,000 households and their members (aged fifteen and over) from the seven metropolitan cities and urban areas in eight provinces (excluding Jeju Island). ${ }^{5}$ Since its fourth-year survey in 2001, the KLIPS has been collecting data on intergenerational transfers given to and received from parents. Related questions are separately asked for the household head's parents and for the spouse's parents. Using these questions, we know financial transfers in the last year given to and received from parents and parents-in-law who do not live with respondents and spouses. The average age of the KLIPS household heads is 45.4 in 2005.

Table 7.3 shows that at least 50 percent of KLIPS households make transfers to their parents or parents-in-law; however, the fraction of households who report transfer receipts from their parents or parents-in-law is at most 24 percent. Compared with the KLoSA data in table 7.1, the KLIPS data

5. The data and documentations of the KLIPS can be downloaded at the website of Korea Labor Institute (www.kli.re.kr). 


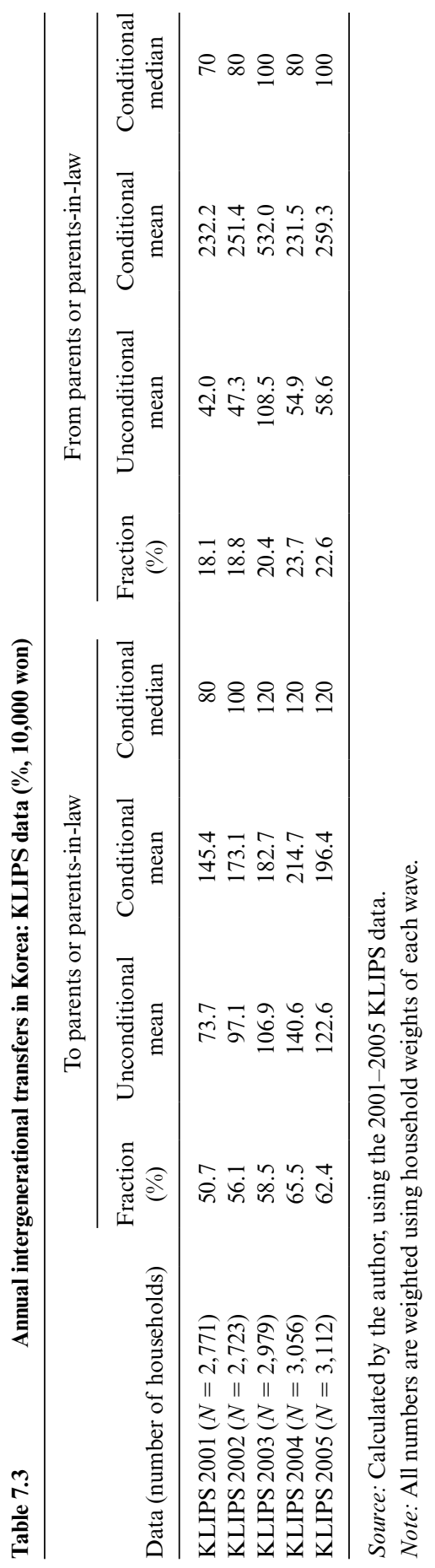


report more prevalent, sizable transfers between parents and children. But it should be accounted for that the intergenerational transfers from the KLIPS data in table 7.3 include financial help from/to the spouses' parents as well as the household heads' parents, whereas those from the KLoSA data in table 7.1 do not include transfers from/to parents-in-law. In addition, unlike the KLoSA survey, the intergenerational transfers in the KLIPS survey include monetary value of in-kind transfers such as food or electronic appliances (evaluated at the purchase price). ${ }^{6}$

By its survey structure, the KLIPS provides an opportunity to investigate potential differences between transfers from/to the husband's parents and those from/to the wife's parents by separating them using information on the household head's gender. ${ }^{7}$ Table 7.4 reveals that Korean households tend to give a larger amount of transfers (in terms of both average and median) to the husband's parents than to the wife's parents. As for the median amount of transfer gifts from parents, however, we do not observe such differences between the head's parents and the wife's parents. This gender difference might reflect asymmetric standings of the husband and the wife in their earnings and decision-making powers in the family. But it surely reflects traditional norms under which elderly parents have been supported mainly by their sons (especially their eldest sons) rather than their daughters.

\section{KReIS Data}

The Korean Retirement and Income Study (KReIS) started in 2005 to be conducted every odd-numbered year. The KReIS survey has the purpose of creating a basic data set needed to devise policies for effective old-age income security. The sample consists of nationally representative 5,110 households that have at least one person aged fifty or older (an "age-eligible respondent"). In addition, the KReIS included the age-eligible respondent's spouse irrespective of his/her age, resulting in a total sample of 8,689 respondents.

In the $2005 \mathrm{KReIS}$ data, private transfers received by and given by the respondent or the spouse during the last calendar year (2004) are asked. Unlike the KLoSA and the KLIPS data, the KReIS reports transfers between the respondent (or the spouse) and coresident family members as well as noncoresident family members. According to the KReIS questionnaire, transfers include financial help in the form of money or in-kind transfers for living, schooling, and so forth, but do not include occasional gifts such as for birthdays or holidays.

6. By contrast, the KLoSA survey asked about in-kind transfers using separate questions on "nonmonetary" transfer. Suggested types of nonmonetary support in the questionnaire is leisure (e.g., travel), health-related products (e.g., vitamins, equipments, etc.), household items, electronics, dining out and foods, and other. But their monetary values are not reported.

7. The proportion of females among the KLIPS household heads has increased gradually: 15.3 percent in 2001, 16.0 percent in 2002, 18.0 percent in 2003, 18.3 percent in 2004, and 19.6 percent in 2005. 


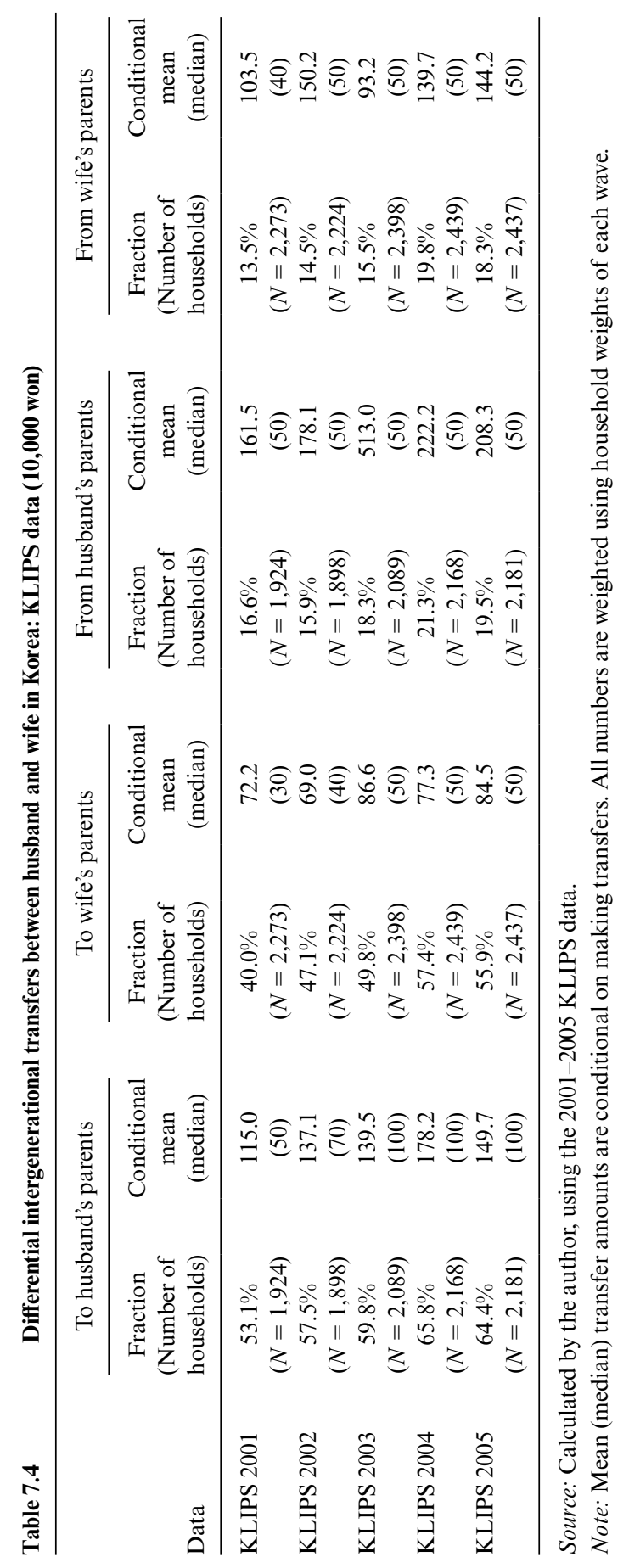


Since private transfers are reported for every age-eligible respondent or spouse in the household, some households have multiple observations of different amounts of transfers when there are multiple respondents or couples in the same household. Thus, I specify a "financial respondent" for each household by naming the household head first, and then the spouse if the head is not a respondent, and then the head's parent if both are not respondents, and so on following the frequency of the respondent's relationship with the head in the data. The resulting age-eligible financial respondents, who were aged 64.9 on average in 2005 , provide 4,800 household observations on private transfers.

Table 7.5 tabulates annual transfer receipts and gifts by the relationship of donors and recipients. The proportion of those who received transfers from noncoresident children is 45.8 percent, while that from coresident children is 16.5 percent. Because coresidence is another important way of supporting elderly parents and also because some coresident children may be still dependent on their parents, fewer coresident children tend to give transfers to their parents than their noncoresident siblings. The mean amount of transfer receipt from noncoresident children is $1,380,000$ won and the conditional mean (median) amount is $3,010,000(1,500,000)$ won.

The proportion of respondents who gave transfers to coresident children is 23.8 percent and the conditional mean (median) amount of transfer gift is $7,300,000(6,000,000)$ won. This sizable amount may reflect parents' help for dependent children (e.g., college tuition help) who are relatively young compared to noncoresident children. In terms of mean amounts of transfer receipt and gift, coresident children tend to be "net receivers" whereas noncoresident children tend to be "net givers" from whom parents receive $950,000(=1,380,000-430,000)$ won, on average, a year.

Time is also transferable between family members through informal caregivings. Given that family caregivings are substitutes for formal caregivings that can be purchased from the market in many cases, intergenerational caregivings often have similar effects on the recipient with intergenerational financial help. Specifically, the KReIS data report respondents' childcare for their grandchildren and caregivings for their sick parents. As Table 7.6 shows, about 15 percent of age-eligible financial respondents or their spouses are currently looking after their grandchildren almost entirely, and their average (median) child care hours are fifty-four (forty-nine) hours a week - the equivalent of having a full-time job with no weekend and holiday. At the same time, 15 percent of grandparents said that they had an experience of quitting paid work or reducing the amount of time they worked in order to look after their grandchildren. Of those who provide child care services, two-thirds offer their services for free. The rest receive money with mean (median) amounts 360,000 $(300,000)$ won a month, which suggests that some intergenerational transfers from adult children to elderly parents are motivated by an exchange motive-child care service for money. 


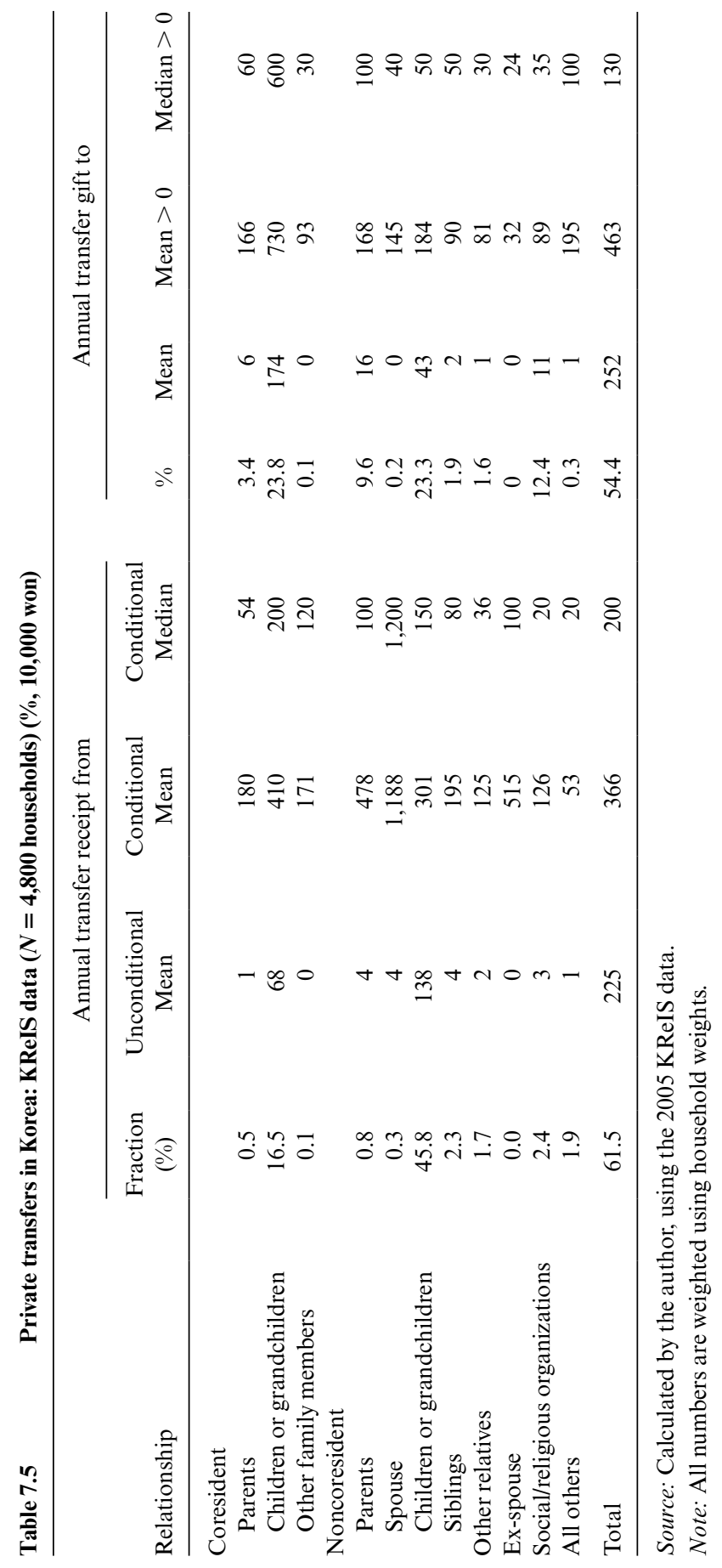


Table 7.6

Family caregivings in Korea: KReIS data

\begin{tabular}{lcc}
\hline Caregivings for & $\begin{array}{c}\text { Grandchildren } \\
(N=3,290 \text { households } \\
\text { that have grandchildren })\end{array}$ & $\begin{array}{c}\text { Sick parents } \\
(N=1,431 \text { households } \\
\text { whose parents are alive })\end{array}$ \\
\hline $\begin{array}{l}\text { Proportion of caregiving households } \\
\begin{array}{l}\text { Mean (median) caregiving hours per week } \\
\text { Proportion of caregivers who had to quit } \\
\text { or reduce work for caregiving }\end{array}\end{array}$ & $\begin{array}{c}14.7 \% \\
(49) \text { hours }\end{array}$ & $\begin{array}{c}7.0 \% \\
\text { Proportion of caregivers who receive money } \\
\text { for caregiving }\end{array}$ \\
$\begin{array}{l}\text { Mean (median) amount of money received } \\
\text { for caregiving per month }\end{array}$ & $15.2 \%$ & $26.3 \%$ \\
\hline
\end{tabular}

Source: Calculated by the author, using the $2005 \mathrm{KReIS}$ data.

Note: All numbers are weighted using household weights.

On the other hand, 7 percent of age-eligible financial respondents or their spouses are currently taking care of their sick parents and their average (median) caregiving hours are thirty-seven (twenty-one) hours a week. About 26 percent had an experience of quitting paid work or reducing the amount of time they worked in order to care for their sick parents.

\section{Intergenerational Transfers in the United States: HRS Data}

Now let us look at comparative data for the United States on intergenerational transfers. Among others, the Health and Retirement Study (HRS) provides useful information on financial transfers between parents and children. The HRS is a national panel study with an initial sample of 7,607 households $(12,652$ persons who were fifty-one to sixty-one years old in 1992). ${ }^{8}$ To compare annual familial transfers between the United States and Korea, I use the first two waves of the HRS $(1992,1994)$ that report intergenerational transfers made in the past twelve months. ${ }^{9}$ The 1992 wave of the HRS asked about financial assistance given to the parents and children of the respondent or spouse totaling 500 dollars or more in the past twelve months. ${ }^{10}$ In the 1994 wave, the censoring amount was changed to 100 dollars, and financial assistance received from their parents and children was also reported.

Panel A and panel B in table 7.7 report the 1992/1994 HRS respondents' transfer gifts to their parents or parents-in-law and those to their children, respectively. Both waves of the HRS data show that the respondents make

8. The baseline 1992 survey consisted of in-home, face-to-face interviews with the 1931 to 1941 birth cohort and their spouses, if married. Follow-up interviews were given by telephone in 1994, 1996, 1998, 2000, 2002, 2004, and 2006.

9. In waves 3 through 8 the questions on financial transfers asked about transfers exceeding $\$ 500$ in the past two years.

10. The financial help in the HRS data includes help with education but it does not include any shared housing or shared food, which is the same as the KLoSA data. 
Annual intergenerational transfers in the United States: HRS 1992/1994 data (U.S. dollar in each year)

\begin{tabular}{lcccc}
\hline Data (censoring amount) & Fraction $\%(\mathrm{~N})$ & $\begin{array}{c}\text { Unconditional } \\
\text { mean }\end{array}$ & $\begin{array}{c}\text { Conditional } \\
\text { mean }\end{array}$ & $\begin{array}{c}\text { Conditional } \\
\text { median }\end{array}$ \\
\hline & A. To parents or parents-in-law & & \\
HRS 1992 (\$500 or more) & $10.8(2,180)$ & 208 & 1,929 & 1,000 \\
HRS 1994 (\$100 or more) & $16.5(1,985)$ & 89 & 903 & 500 \\
& \multicolumn{7}{c}{ B. to children } \\
HRS 1992 (\$500 or more) & $34.8(3,920)$ & 1,604 & 4,609 & 2,000 \\
HRS 1994 (\$100 or more) & $45.1(3,462)$ & 1,750 & 3,934 & 1,400 \\
& C. From parents or parents-in-law & & \\
HRS 1994 (\$100 or more) & $5.7(1,984)$ & 81 & 2,459 & 1,000 \\
& \multicolumn{2}{c}{ D. From children } \\
HRS 1994 (\$100 or more) & $8.0(3,465)$ & 90 & 1,505 & 600 \\
\hline
\end{tabular}

Source: Calculated by the author, using the 1992/1994 HRS data.

Note: All numbers are weighted using household weights of each wave.

substantial transfers to their children, whereas transfers to their elderly parents are much fewer. Panel C and panel D report the 1994 HRS respondents' transfer receipts from their parents or parents-in-law and those from their children. The fraction of positive transfer receipts is very low from both directions.

To compare Koreans' transfers to their elderly parents with Americans,' we should pay attention to the 1994 HRS statistics in panel A, which are fairly comparable to the KLIPS statistics in table 7.3. Remember that KLIPS respondents are on average younger than HRS respondents, and therefore take the 2005 KLIPS statistics from table 7.3. About 62 percent of Korean households give some transfers to their parents or parents-in-law, and the average amount of transfers conditional on gift is 1,964,000 won (roughly $\$ 2,000$ in 2005 dollars) a year. By contrast, only 16.5 percent of American households make transfers to their parents or parents-in-law, and the average transfer amount conditional on gift is just $\$ 117$ (converted to 2005 dollars) a year.

Using later waves of the HRS, we can also see similar patterns of U.S. familial transfers, which are mostly headed for children and play only a limited role as a supplemental income for the elderly. Table 7.8 shows the fraction of U.S. households making intergenerational transfers exceeding 500 dollars in the last two years over six waves of the HRS survey fielded in 1996, 1998, 2000, 2002, 2004, and 2006. ${ }^{11}$ The proportion of families who

11. The HRS sample was expanded in 1998, and every two years thereafter, by adding the Study of Assets and Health Dynamics Among the Oldest Old (AHEAD) sample and the new subsamples - War Babies (WB) and Children of the Depression (CODA) - to the original HRS sample interviewed previously in 1992, 1994, and 1996. Therefore, the number of households that responded to transfer questions increased substantially in 1998. 
Table 7.8

Fraction of U.S. households making intergenerational transfers exceeding 500 dollars in the last two years ( $\%$ positive fraction [no. of households])

\begin{tabular}{lcccc}
\hline Data & $\begin{array}{c}\text { To children or } \\
\text { grandchildren }\end{array}$ & $\begin{array}{c}\text { From children } \\
\text { or grandchildren }\end{array}$ & $\begin{array}{c}\text { To parents or } \\
\text { parents-in-law }\end{array}$ & $\begin{array}{c}\text { From parents or } \\
\text { parents-in-law }\end{array}$ \\
\hline HRS 1996 & $39.9(6,208)$ & $4.0(6,224)$ & $\begin{array}{c}\text { Husband's parents: } \\
15.0(1,930)\end{array}$ & $\begin{array}{c}\text { Husband's parents: } \\
4.4(1,940) \\
\text { Wife's parents: }\end{array}$ \\
WRS 1998 & $35.6(12,764)$ & $5.2(12,802)$ & $13.9(2,960)$ & $6.0(2,961)$ \\
HRS 2000 & $35.7(11,859)$ & $5.9(11,878)$ & $13.5(3,900)$ & $7.2(3,902)$ \\
HRS 2002 & $31.3(12,038)$ & $6.2(12,049)$ & $15.3(3,374)$ & $7.1(3,372)$ \\
HRS 2004 & $37.9(12,281)$ & $6.5(12,315)$ & $14.3(4,299)$ & $5.6(4,307)$ \\
HRS 2006 & $36.3(11,494)$ & $6.4(11,521)$ & $17.7(5,859)$ & $6.9(5,856)$ \\
\hline
\end{tabular}

gave positive transfers to children is always over 30 percent, which is more than double the proportion of families who gave positive transfers to elderly parents.

Compared to Korean families in tables 7.1, 7.3, and 7.5, among which at least 40 percent give transfers to elderly parents in the last twelve months, fewer American families make such transfers, at most 17 percent, even in the last twenty-four months. This may reflect a cultural difference between two countries in that Korea has a tradition of extended families and Confucian ethics that requires children's responsibility of supporting their elders. But it may also reflect that even without help from children, American elderly can have relatively sufficient income from their savings or Social Security benefits. $^{12}$

Also, unlike Korean families who exhibit noticeable gender differences in transfer behavior toward the husband's parents and the wife's parents (table 7.4), American families in the HRS data do not clearly show such differences. The 1996 wave of the HRS reports financial assistance from/to parents and parents-in-law separately. I identify the husband's parents and the wife's parents based on the family respondent's gender. The fraction of households who made transfers to the wife's parents is 14 percent, similar to the fraction of 15 percent for the husband's parents. ${ }^{13}$

12. For instance, the sources of American elderly household income as of 1984 for the highest and lowest income quintiles are as follows (Hurd 1990, table 12). The highest quintile households' average income of $\$ 34,061$ consists of $\$ 9,450$ earnings (27.2 percent), $\$ 13,289$ property income (39.0 percent), $\$ 5,901$ Social Security benefits (17.3 percent), and $\$ 5,421$ other income (15.9 percent). The lowest quintile households' average income of $\$ 3,986$ consists of $\$ 73$ earnings (1.8 percent), \$168 property income (4.2 percent), \$3,102 Social Security benefits (77.8 percent), and $\$ 643$ other income (16.1 percent). These amounts are in 1982 dollars and adjusted for family size.

13. The conditional mean (median) amount of positive transfer given to the husband's parents is $\$ 3,406(\$ 1,500)$ and that from the wife's parents is $\$ 2,639(\$ 1,000)$. The conditional mean (median) amount of positive transfer received from the husband's parents is $\$ 5,370(\$ 2,000)$ 
Inheritances ever received: KLoSA and HRS data

\begin{tabular}{|c|c|c|c|}
\hline Data sample (no. of households) & $\begin{array}{l}\text { Percentage of the } \\
\text { households that } \\
\text { have ever inherited }\end{array}$ & $\begin{array}{l}\text { Mean amount } \\
\text { conditional on } \\
\text { receipt }\end{array}$ & $\begin{array}{c}\text { Median amount } \\
\text { conditional on } \\
\text { receipt }\end{array}$ \\
\hline $\begin{array}{l}\text { KLoSA } 2006 \\
\quad \text { All households }(N=6,171)\end{array}$ & 2.4 & $\begin{array}{c}\# 150,658,000 \\
(\$ 157,665 \text { in } 2006)\end{array}$ & $\begin{array}{c}\# 50,000,000 \\
(\$ 52,325 \text { in } 2006)\end{array}$ \\
\hline $\begin{array}{l}\text { KLoSA } 2006 \\
\quad \text { Age } 51-61 \text { cohort }(N=1,781)\end{array}$ & 3.3 & $\begin{array}{c}\# 201,659,000 \\
(\$ 211,038 \text { in } 2006)\end{array}$ & $\begin{array}{c}\$ 80,000,000 \\
(\$ 83,721 \text { in } 2006)\end{array}$ \\
\hline $\begin{array}{l}\text { HRS } 1992 \\
\quad \text { Age } 51-61 \text { cohort }(N=7,538)\end{array}$ & 28.1 & $\begin{array}{c}\$ 50,818 \\
(\$ 73,021 \text { in 2006) }\end{array}$ & $\begin{array}{c}\$ 20,000 \\
(\$ 28,738 \text { in } 2006)\end{array}$ \\
\hline
\end{tabular}

Notes: In converting won (\#) to dollar (\$) amount, I use the year-average exchange rate in 2006 (1 dollar $=955.56$ won) from the Bank of Korea. The 1992 dollar amounts are converted to the 2006 dollars using the Consumer Price Index.

\subsubsection{Inheritances}

\section{Inheritances Ever Received}

The 2006 KLoSA survey asks about money or property that the respondent has ever received in the form of an inheritance, a trust fund, or an insurance settlement. As shown in table 7.9, the fraction of KLoSA households who have ever received any of these is only 2.4 percent. ${ }^{14}$ However, the magnitude of inheritance is quite sizable. The mean and median amounts of inheritances conditional on receipt are about 151 million won $(\$ 158,000)$ and 50 million won $(\$ 52,000)$, respectively.

The 1992 HRS survey contains a similar question on inheritance receipt, which reads: "Have you [or your (husband/wife/partner)] ever received an inheritance, or been given substantial assets in the form of a trust?"15 The fraction of HRS households who have ever received an inheritance is 28 percent. The mean and median amounts of inheritances conditional on receipt are about $\$ 51,000$ and $\$ 20,000$, respectively.

Considering different age distributions of the 2006 KLoSA (age fortyfive or over) and the 1992 HRS (age fifty-one to sixty-one) respondents, in the middle row of table 7.9, I restrict the KLoSA sample to those who were

and that from the wife's parents is $\$ 6,334(\$ 3,000)$. So if I were to point out anything at all, the wife's parents appear to receive slightly less and give slightly more than the husband's parents in the United States.

14. To compare with the HRS data that report inheritances that the respondent or spouse has ever received, I add up a couple's inheritance receipts if both are KLoSA respondents and therefore both report their inheritances. But if the spouse is not an eligible KLoSA respondent (probably because younger than forty-five years old), her or his inheritance receipt cannot be counted in.

15. The 1992 HRS data report the following three receipts separately: (a) an inheritance or a trust; (b) money or assets totaling $\$ 10,000$ or more; and (c) a life insurance settlement of $\$ 10,000$ or more. I add up these three forms of receipts and find that among 7,538 respondents the number of people with zero, one, two, and three forms of receipts is 5,420,1,908, 203, and 7 , respectively. 
aged between fifty-one and sixty-one at the time of survey. Compared to the whole KLoSA sample, this subsample reports a higher fraction of positive receipts and a larger conditional mean and median. Nevertheless, there still exists a sharp contrast between the HRS and the KLoSA in inheritance patterns.

According to the table, Korean parents tend to concentrate their bequests on a child (arguably the eldest son who has taken care of them in their old age), which limits the number of inheritors to a small fraction but increases the amount of inheritance. On the contrary, American parents are known to distribute their estates almost equally among their children. ${ }^{16}$

In light of this, we may infer that, together with traditional norms of filial piety, potential bequests could have been used as leverage for Korean parents to get old-age support from their children, or their eldest sons to be more specific. A cross-cultural study by Shin, Cho, and Walker (1997) also finds that Korean children and their parents (specifically, mothers and mothersin-law in their study) are more likely to endorse distributing larger shares of inheritance to the child who cares for her/his parents than American counterparts.

The KLoSA data also report the form of the largest inheritance receipt and the relationship of its donor to the recipient. Table 7.10 shows that about 70 percent of donors are recipients' fathers, which may reflect that the household head has the ownership of major household properties like a house. The form of the largest amount of inheritance is real estates in most cases. This implies that the most common case of inheritance in Korea is the eldest son's inheriting his parents' house or land when they died, finishing their coresidence with him. The eldest son is more likely to stay with his elderly parents after marriage than any other child in the family (see table 7.18 in section 7.4). Therefore, Korean parents have been able to provide a material incentive for the child who takes care of them in old age (mostly the eldest son) using their house as a promising inheritance.

The KReIS data report inheritances that respondents and spouses have ever received and bequests that they have ever left. Table 7.11 shows that 28.6 percent of the age-eligible financial respondents' households received inheritances, which is a much larger proportion compared to the KLoSA households in table 7.9, but quite similar to the HRS households. This discrepancy between the KReIS data and the KLoSA data in terms of the fraction of households receiving inheritances may arise at least in part from the fact that these two data sets use different wordings in their questions on inheritance. The KReIS asks about inheritances received by the spouse as well as the respondent, and explicitly refers to land or a house- the most

16. For example, Wilhelm (1996) finds that 68.6 percent of decedents divide their estates exactly equally between their children, and 76.6 percent divide their estates so that each child receives within 2 percent of the average inheritance across all children. McGarry (1999) also finds that bequests are mostly shared equally, whereas inter-vivo transfers tend to be more compensatory. 
Who leaves what as an inheritance in Korea? KLoSA data

\begin{tabular}{lclc}
\hline Relationship of donor & No. of cases $(\%)$ & Form of inheritance & No. of cases (\%) \\
\hline Father & $99(67.8)$ & Real estate & $137(93.8)$ \\
Spouse & $28(19.2)$ & Cash or financial assets & $5(3.4)$ \\
Mother & $12(8.2)$ & Insurance settlement & $2(1.4)$ \\
Father-in-law or mother-in-law & $4(2.7)$ & Pension settlement & $1(0.7)$ \\
Other relative & $3(2.1)$ & Other & $1(0.7)$ \\
Total & $146(100.0)$ & Total & $146(100.0)$ \\
\hline
\end{tabular}

Table 7.11

Inheritances and bequests in Korea: KReIS data $(N=\mathbf{4 , 8 0 0}$ households)

\begin{tabular}{|c|c|c|c|}
\hline \multicolumn{2}{|c|}{ Inheritances ever received } & \multicolumn{2}{|c|}{ Bequests ever left } \\
\hline Proportion of recipients (\%) & 28.6 & Proportion of donors $(\%)$ & 31.7 \\
\hline Donor & $\%$ donor $^{\mathrm{a}}$ & Main recipient & $\%$ main recipient \\
\hline \multirow{7}{*}{$\begin{array}{l}\text { Parents } \\
\text { Parents-in-law } \\
\text { Grandparents } \\
\text { Grandparents-in-law } \\
\text { Spouse (deceased) }\end{array}$} & \multirow{4}{*}{79.3} & Eldest son & 52.6 \\
\hline & & Evenly to every child & 17.6 \\
\hline & & Eldest daughter & 15.5 \\
\hline & & Noneldest son & 9.3 \\
\hline & \multirow[t]{3}{*}{21.1} & Noneldest daughter & 3.5 \\
\hline & & Social organization & 0.6 \\
\hline & & Sibling & 0.1 \\
\hline
\end{tabular}

Source: Calculated by the author, using the 2005 KReIS data.

Note: All numbers are weighted using household weights.

aThe sum of " $\%$ donor" is 100.4 because a few households received inheritances from both their parents and their spouses.

common form of inheritances in Korea. Looking at bequests that the KReIS respondents and spouses have ever left, we can find that the tradition of primogeniture still prevails but different patterns also make an appearance. The proportion of the eldest son as the main recipient of bequests is 52.6, still more than half, but the proportion of equal distribution across children is now the second most frequent case.

\section{Expectation about Inheritances}

While having not yet received any inheritance, people may expect to receive inheritances in the future. They may also expect to leave bequests. The KLoSA and the HRS surveys have questions on subjective expectations about inheritances..$^{17}$ Table 7.12 reports such expectations. The sample mean of the subjective chances that the KLoSA respondents will receive inheri-

17. The related KLoSA questions read: "Including property and other valuables that you might own, what are the chances that you will leave an inheritance totaling 100,000,000 Korean won or more? And how about the chances that you will receive an inheritance totaling $100,000,000$ Korean won or more?" The corresponding HRS questions read: "What are the 
Table 7.12 Subjective expectations about inheritances: KLoSA and HRS data

\begin{tabular}{|c|c|c|}
\hline Data & Chances of receiving an inheritance & Chances of leaving a bequest \\
\hline KLoSA 2006 & $\$ 100,000,000$ or more: $0.17(N=3,163)$ & $\# 100,000,000$ or more: $0.38(N=10,254)$ \\
\hline \multirow[t]{2}{*}{ HRS 1994} & $0.21(N=5,905)$ & $\$ 10,000$ or more: $0.60(N=5,901)$ \\
\hline & Mean (median) amount: $\$ 51,127(\$ 20,000)$ & $\$ 100,000$ or more: $0.42(N=5,139)$ \\
\hline \multirow{2}{*}{ HRS 1996} & $0.20(N=6,316)$ & $\$ 10,000$ or more: $0.65(N=6,309)$ \\
\hline & Mean (median) amount: $\$ 62,996(\$ 25,000)$ & $\$ 100,000$ or more: $0.44(N=4,885)$ \\
\hline \multirow[t]{2}{*}{ HRS 1998} & $0.18(N=6,027)$ & $\$ 10,000$ or more: $0.65(N=6,000)$ \\
\hline & Mean (median) amount: $\$ 75,220(\$ 25,000)$ & $\$ 100,000$ or more: $0.45(N=4,778)$ \\
\hline \multirow[t]{2}{*}{ HRS 2000} & $0.17(N=5,697)$ & $\$ 10,000$ or more: $0.66(N=5,660)$ \\
\hline & Mean (median) amount: $\$ 172,661(\$ 20,000)$ & $\$ 100,000$ or more: $0.48(N=4,563)$ \\
\hline
\end{tabular}

tances exceeding $100,000,000$ won is 0.17 , which is much higher than the fraction of the KLoSA households that have ever inherited in table 7.9. This subjective probability is quite comparable to the HRS respondents' expectations in table 7.12, although the HRS questions did not give any censoring amount (herein a lower limit) to the respondents. Therefore, the KLoSA respondents appear to have more optimistic expectations about substantial amounts of inheritance receipts than the HRS respondents. As for the subjective probability of leaving an inheritance exceeding $100,000,000$ won (roughly $\$ 100,000$ in 2006), the KLoSA respondents report 0.38 on average and the corresponding HRS figures range from 0.42 to 0.48 .

Considering substantial differences between the KLoSA and the HRS in terms of inheritance receipts, their expectations about inheritances seem fairly similar to each other. This probably suggests that Koreans' behaviors toward inheritances are getting closer to Americans'. That is, Koreans' bequests are being more equally distributed among children, as the eldest son's burden of supporting elderly parents is being distributed to a broader range of supporters, including other sons, daughters, and parents themselves (see table 7.19 in section 7.4). Incidentally, high chances that Koreans expect to leave sizable inheritances exceeding 100,000,000 won might reflect the recent housing market boom in Korea, considering that the most common form of their inheritance is real estate.

\subsection{Characteristics of Donor and Recipient}

Intergenerational transfers given by adult children to their elderly parents have played a crucial role in the old-age income security in Korea. As shown in the previous section, Korean elderly parents are more likely to be net ben-

chances that you [or your (husband/wife/partner)] will leave an inheritance totaling $\$ 10,000$ $[\$ 100,000]$ or more? And how about the chances that you will receive an inheritance within the next 10 years? About how large do you expect that inheritance to be?" 
eficiaries in financial exchanges with their children. This section investigates the characteristics of the donor and the recipient to better understand the motivation and other realities of familial transfers in Korea.

First, I introduce a simple model of intergenerational transfers for setting up a basic specification of empirical models and review existing empirical results. Based on these backgrounds, I examine parents' characteristics as the explanatory variables in the regressions of the parents' net transfer receipt from their children. Then I examine children's characteristics using family fixed-effect models to figure out which child will provide the largest financial help, which is what many parents are probably curious about.

\subsubsection{Background}

The theoretical framework in this section is adopted from Cox, Hansen, and Jimenez (2004). Consider a family in which financial transfers are made between two family members. For simplicity, I assume that the "net giver" whose transfer gift is bigger than transfer receipt has an altruistic preference, while the "net receiver" does not. So the two family members are assumed to consist of an altruistic donor and a nonaltruistic recipient.

Suppose the utility of the donor, $U_{d}$, is given by:

$$
U_{d}=U\left(C_{d}, s, V\left(C_{r}, s\right)\right),
$$

where $V$ is the well-being of the recipient; $C_{d}$ and $C_{r}$ are consumption levels for the donor and the recipient, respectively; and $s$ denotes "services" that the recipient might provide to the donor. ${ }^{18}$ The donor's altruistic motive is indicated by $\partial U / \partial V>0$. Exchange motives may be present as well if the donor values services from the recipient, $\partial U / \partial s>0$, and the recipient's utility falls with provision of services, $\partial V / \partial s<0$.

The budget constraints for donor and recipient can be written:

$$
C_{d}=I_{d}-T \text { and } C_{r}=I_{r}+T,
$$

where $T$ denotes financial transfers given by the donor to the recipient; and $I_{d}$ and $I_{r}$ are pretransfer incomes of the donor and the recipient, respectively. Since $C_{r}$ is a normal good for the donor, transfers are increasing in the donor's pretransfer income, $\partial T / \partial I_{d}>0$.

If transfers are altruistically motivated, we expect $\partial T / \partial I_{r}<0$ because the donor believes that the recipient with higher (lower) pretransfer income requires smaller (larger) transfers to attain the optimal level of consumption. Instead, if transfers are exchange-motivated, the relationship between $T$ and $I_{r}$ will be ambiguous. Suppose transfers are payments for services that the

18. Cox, Hansen, and Jimenez (2004) consider "services" as a catchall term standing for anything provided by the recipient in return for the money received from the donor. It can be, for example, help with home production, babysitting, visiting, caregiving, behaving in a way the donor prefers, or future financial transfers as the discounted value of repayments if the money received from the donor is a loan. 
donor purchases from the recipient at an implicit price, $p$, so that $T=p s$. Cox (1987) shows $\partial s / \partial I_{r}<0$ and $\partial p / \partial I_{r}>0$; that is, a richer recipient will provide smaller services to the donor, and the donor has to pay a higher price for the services provided by a richer recipient. Therefore, transfers can rise or fall with $I_{r}$, depending on whether the price effect dominates the quantity effect. In this case, the functional form of transfers in the recipient's pretransfer income will be nonlinear.

As seen in the previous section, the dominant direction of private transfers in the United States is downward; therefore, most empirical studies using U.S. data focus on the motivation of parental transfers to their children rather than adult children's transfers to their elderly parents. The extensive empirical literature comes to mixed conclusions on whether inter-vivos transfers are compensatory or not. McGarry and Schoeni (1995, 1997), Dunn and Phillips (1997), McGarry (1999, 2000), and Hochguertel and Ohlsson (2000), for example, report that parental transfers compensate worse-off children. But Laferrère and Wolff (2004) discuss some empirical studies providing evidence against compensatory transfers and rejecting altruism. Cox (1987), Cox and Rank (1992), and Cox, Eser, and Jimenez (1998) also suggest that transfers may represent payment to the recipient for the provision of services rather than altruism. Cox and Jakubson (1995) even argue that the anti-poverty effectiveness of public transfers can be magnified by private-transfer responses that are basically exchange-motivated.

By contrast, the direction of familial transfers observed in Korean data sets is more likely to be upward; as a result, this study has a different angle. In the remaining parts of this section, I estimate the familial transfer model in which adult children are net givers and their elderly parents are net receivers. If children's transfers are made in a compensatory fashion from their altruistic motive, an increase in their parents' pretransfer income, for example, by public assistance leads to a decrease in their transfers to the parents. This altruism story and resultant crowding-out of private transfers by public transfers are supported in Korean empirical studies by Kang and Jeon (2005) and Kim (2006). But Jin (1999) and Sung (2006) do not find such evidence.

\subsubsection{Which Parents Benefit More from Children?}

Here I examine parental characteristics as explanatory variables for net transfer receipt from children. The regression results using data from the KLoSA and the KReIS are provided in turn.

\section{KLoSA Regression Results}

In the 2006 KLoSA data, financial transfers received from and given to each child in 2005 are reported by the respondent of the Children section in the survey. Regular transfers and irregular (or occasional) transfers are added up to construct total transfers. I calculate net total annual transfer 
receipt from each child by subtracting total annual transfer gift to the child from total annual transfer receipt from the child. Then I sum up net total annual transfer receipt from every child of the respondent to generate the sum of net total annual transfer receipt of the respondent as the dependent variable.

The simple model discussed previously provides some guidance to the empirical specifications of transfer functions. First, as long as we do not know the motivation of transfers ex ante, the functional form of transfers needs to be nonlinear in the recipient's pretransfer income. After trying polynomials of the third and the fourth order that turned out inappropriate in criteria of statistical significance, I choose a quadratic function. Second, considering heterogeneous budget constraints depending on household characteristics given pretransfer incomes, I control for the recipient's age, gender, family size, education level, wealth, health status, work status, and region of residence. Third, in order to account for differential numbers of donors in a family, we need to control for the number of children of the respondent; I further control for the number of daughters and sons separately to address potential gender differences in supporting elderly parents. Finally, I attempt to address other observed characteristics that might affect transfer behavior, such as religious preference, the number of grandchildren, expectations about financial situation of recipients and their children, and expectations about public support for their old age.

Baseline regression results are reported in columns (a) and (b) of table 7.13. First, transfer surplus (i.e., the sum of net total annual transfer receipt from every adult child in the family) increases with the recipient's age until the late seventies, and then decreases. Remember that a similar pattern is also found in the transfer in/out profiles by parent age in table 7.2. Female respondents report more transfer surplus from their children, conditional on their marital status.

Second, transfer surplus is negatively correlated with the recipient's income for almost the entire range of their income distribution. The recipient's net worth also reduces transfer surplus. These results clearly show the main motivation of familial transfers in Korea - an altruistic motive to alleviate the recipient's financial difficulties. ${ }^{19}$

Third, the son provides bigger financial help to the parents than the daughter. The parameter estimates for the number of sons and the number of daughters in column (a) suggest that one more son gives his parents additional transfer surplus of 346,000 won while one more daughter gives her

19. As mentioned earlier, using the KLIPS data, Kim (2006) also concludes that private transfers are altruistically motivated in Korea, from findings that private transfer receipts are negatively correlated with the recipient income and they are crowded out by public assistance. Moreover, Kim (2006) finds qualitatively similar results when both the donor's and the recipient's characteristics, including their incomes, are controlled for using a split-off children sample. 


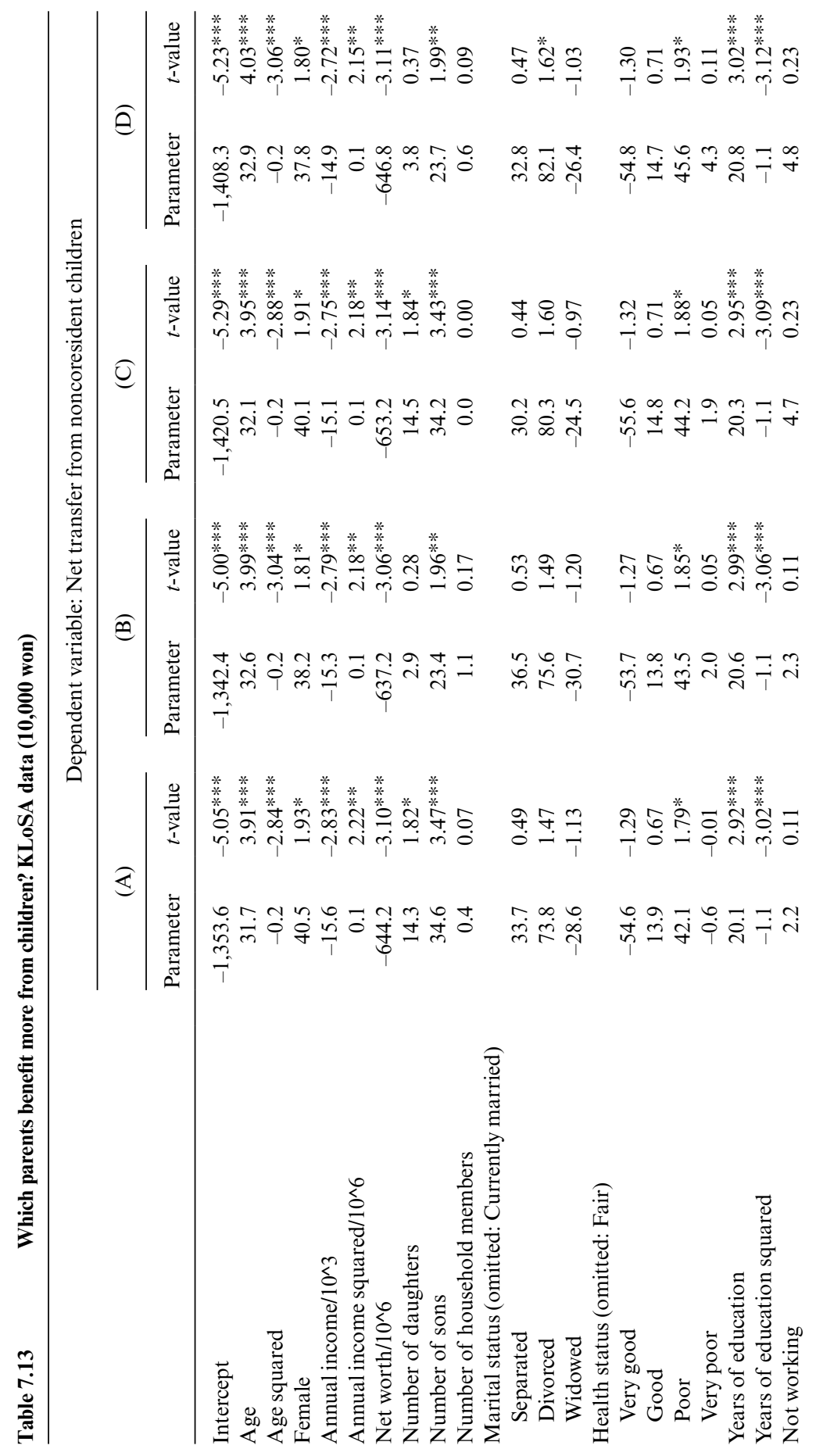




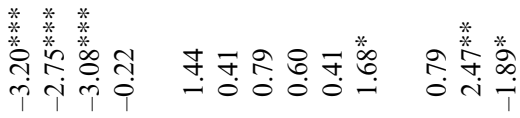

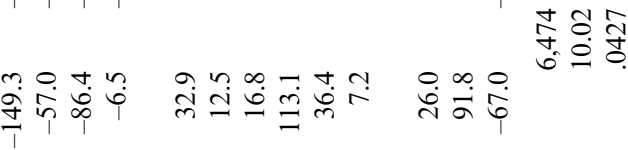

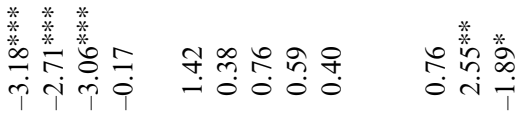

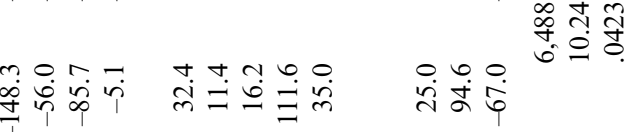

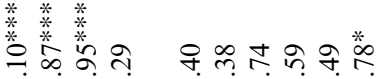

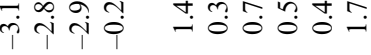

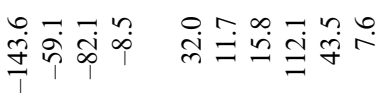

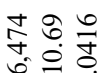

* * * *

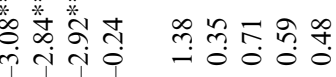

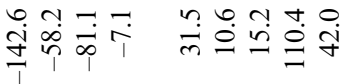

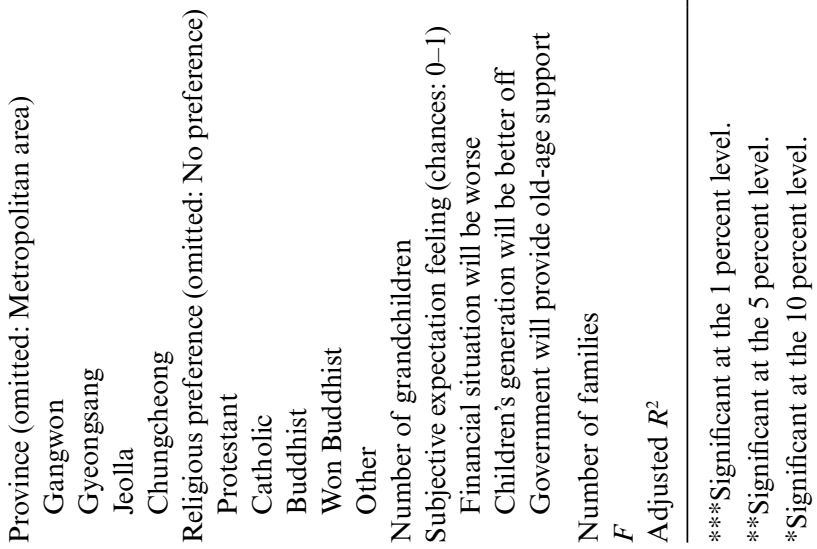


parents additional transfer surplus of 143,000 won. When the number of the recipient's grandchildren is included in the set of explanatory variables as in column (b), the magnitudes of the coefficients for the number of sons and the number of daughters are reduced significantly so that one more daughter, in particular, does not increase transfer surplus anymore. Therefore, one may imagine that the motivation of daughters' financial transfers to their elderly parents is closely related to their children (e.g., in return for grandparents' babysitting service).

Fourth, parental education level increases transfer surplus until nine years of completed schooling (high school entrance level), but further parental education decreases transfer surplus. This nonlinear relationship between parental education and net transfers from children probably reflects the fact that parental education delivers indirect information on their children's economic standings. If undereducated parents tend to have low-income children, parents' additional education implies their children's higher income that can increase net transfers from the children to some levels of parental education. But highly educated parents may not need financial help from their children or are even able to give net transfers to their children, so parental education eventually decreases transfer surplus from a certain level of their education. ${ }^{20}$

Fifth, those who live in the Metropolitan area (Seoul, Incheon, and Gyeonggi province) report a larger transfer surplus than those in other provinces, which probably reflects the recipient's higher living cost and/or the donor's higher income in that area. More transfer surplus seems to go to divorced parents and those who reported their health status as poor. Other parental characteristics such as work status and religious preference do not affect transfer surplus to a degree that has statistical significance.

Furthermore, the KLoSA data contain survey results on respondents' subjective expectation feelings to several issues. Among others, I select their expectations about the financial situation in their future, the relative financial situation of their children's generation compared to theirs, and potential support of their old age by government. These expectations are rescaled between 0 and 1 with an interval of 0.1 and additionally included in the set of explanatory variables in columns (c) and (d) to see how they are correlated with familial transfer behavior.

The results show that expectations on tomorrow's situations affect today's transfer behavior. Those who expect their children's generation will be better off than their generation tend to have more transfer surplus than those

20. The KLoSA data contain detailed information on the respondents' formal educationthe highest level of school they attended and whether they got the diploma, just completed course of study, dropped out, or passed an equivalency test. Using these variables, I construct a variable of imputed years of education that is used in the regressions. According to this variable, the KLoSA respondents have 8.2 years of schooling on average, and 62.5 percent have education levels of nine years or below. 
who do not expect it. They probably make fewer transfers to their children or receive more transfers from their children, who may have similar expectations. A pessimistic expectation about their future financial situation might also yield transfer surplus, but the relationship is not statistically significant. So an expectation about the relative financial situation of the respondents to their children seems more important than an expectation about the absolute level of their own financial situation in determining transfer balance between them.

The most interesting part would be the effect of an expectation about public support on private transfer behavior. The result suggests that those who expect that government will provide old-age support have smaller transfer surplus within their families. They probably make more transfers to their children or receive fewer transfers from their children, who may have similar expectations. As long as familial transfers are not observed by government in general and public transfers are made in a compensatory fashion, this can be regarded as a "moral hazard" behavior.

The crowding-out effect of realized public transfers on private transfers has been documented in the literature (see Kang and Jeon [2005] and Kim [2006], for example), but this potential crowding-out effect of a positive expectation about public transfers on private transfers is first suggested in this study.

\section{KReIS Regression Results}

Since the KReIS survey asked about transfers that respondents or spouses received from and gave to coresident children as well as noncoresident children, table 7.13 reports regression results on net annual transfer receipts by children's coresidence status. ${ }^{21}$ Column (a) uses net transfer receipts from all children irrespective of coresidence status as the dependent variable, and columns (b) and (c) use net transfer receipts from coresident children and from noncoresident children, respectively. Therefore, column (c) results are most comparable to the KLoSA regression results in table 7.12.

In every specification, net transfers are negatively correlated with the recipient's income for almost the entire range of their income distribution, which confirms that Korean familial transfers operate in a compensatory fashion. The crowding-out of noncoresident children's transfers by transfers from coresident children and others listed in table 7.5 also supports the altruism theory. Net worth is also negatively correlated with net transfers, although the relationship is not significant for net transfers from noncoresident children. Parental education level exhibits a nonlinear relationship

21. The unit of analysis here is an individual (or a respondent), not a family. Therefore, I estimate the model with clustered error terms to control for correlation within families and calculate the White-Huber robust standard errors. A household-level analysis using the ageeligible financial respondents' observations yields qualitatively similar results. 
with net transfer receipts from their children, which is also found in table 7.13 of the KLoSA results.

On the other hand, net transfers from coresident children show different relationships with some parental characteristics compared to those from noncoresident children. First, female respondents, household heads, or those who live with their spouses tend to have larger transfer deficits from their coresident children, whereas they tend to have larger transfer surpluses from their noncoresident children.

Second, the age structure of household members has different effects on parents' net transfer receipts by children's coresidence status. The number of household members aged zero to four is positively correlated with net transfers from coresident children but it is negatively correlated with those from noncoresident children. This may reflect coresident children's transfers in return for their parents' babysitting service because coresident infants are probably coresident children's children, not noncoresident children's. The number of household members aged ten to nineteen (and aged twenty to thirty-nine) in the household is negatively correlated with net transfers from coresident children, reflecting parents' substantial expenditure on teenagers (and probably single children in their twenties or thirties) for schooling, private tutoring, clothing, and so on. The number of household members aged forty to sixty-four is negatively correlated with net transfers from noncoresident children, which may suggest that the existence of potential supporters for elderly parents in the household reduces transfers from noncoresident children. ${ }^{22}$

Third, noncoresident sons give more transfers than noncoresident daughters. One more son gives his parents additional transfer surplus of 250,000 won, while one more daughter gives her parents additional transfer surplus of 150,000 won. But coresident children ("net receivers" on average) show no significant difference by gender (see table 7.14).

Finally, more net transfer receipts are reported by those who are caring for their grandchildren (regardless of whether they live together or not) almost entirely. Grandparents who provide extensive caregiving to their grandchildren get more transfer surplus of 1,981,000 won from noncoresident children (probably the grandchildren's parents) than grandparents who do not. This result provides evidence to the existence of exchange motive in familial transfers.

\subsubsection{Which Child Gives More to Parents?}

Now I turn to the child's side to examine the donor's characteristics. We can also control for the donor's and the recipient's observed characteristics

22. Those aged forty to sixty-four may include parents themselves, but the KReIS data do not provide more detailed information on the age structure other than these age categories. 


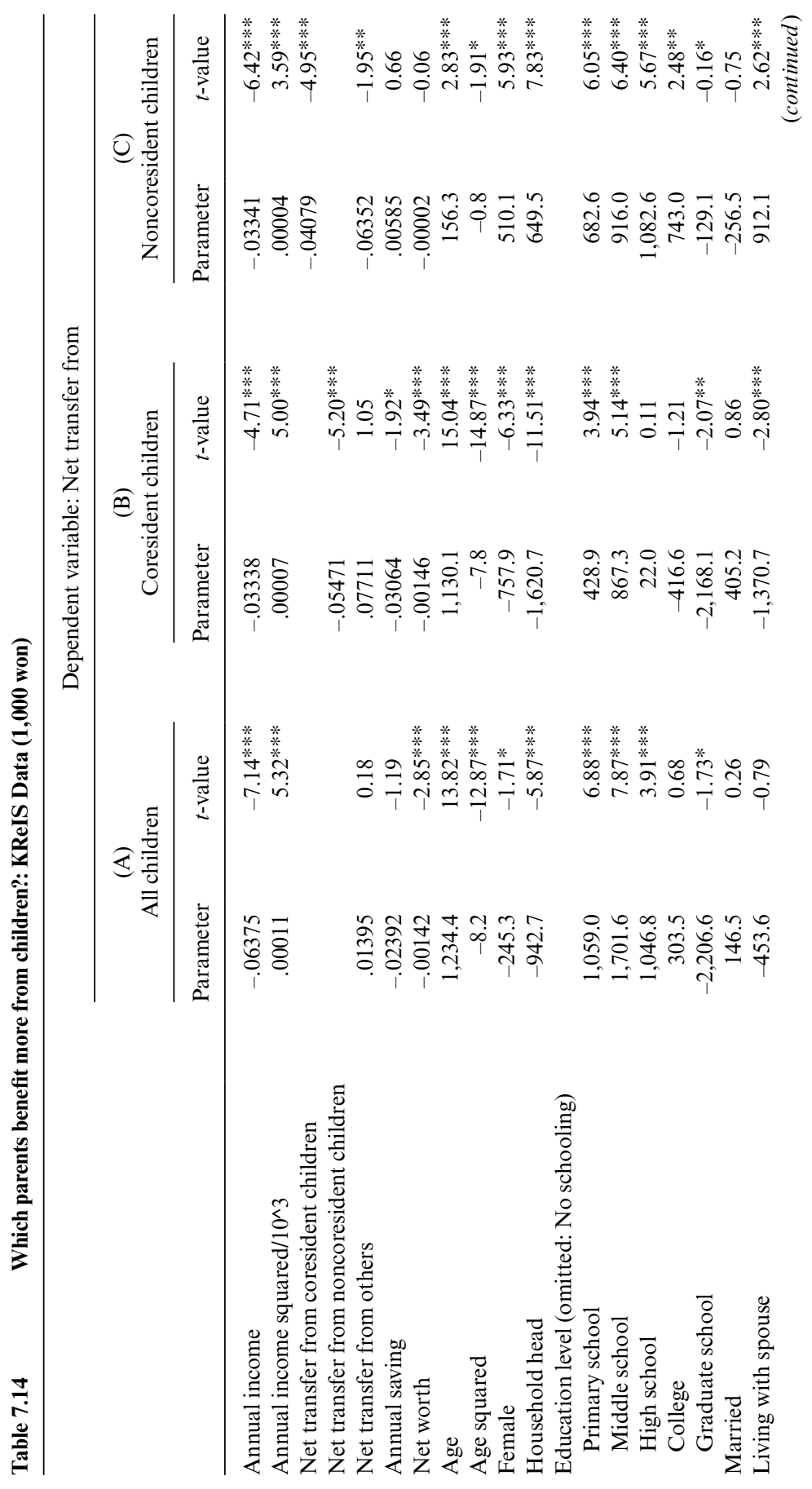




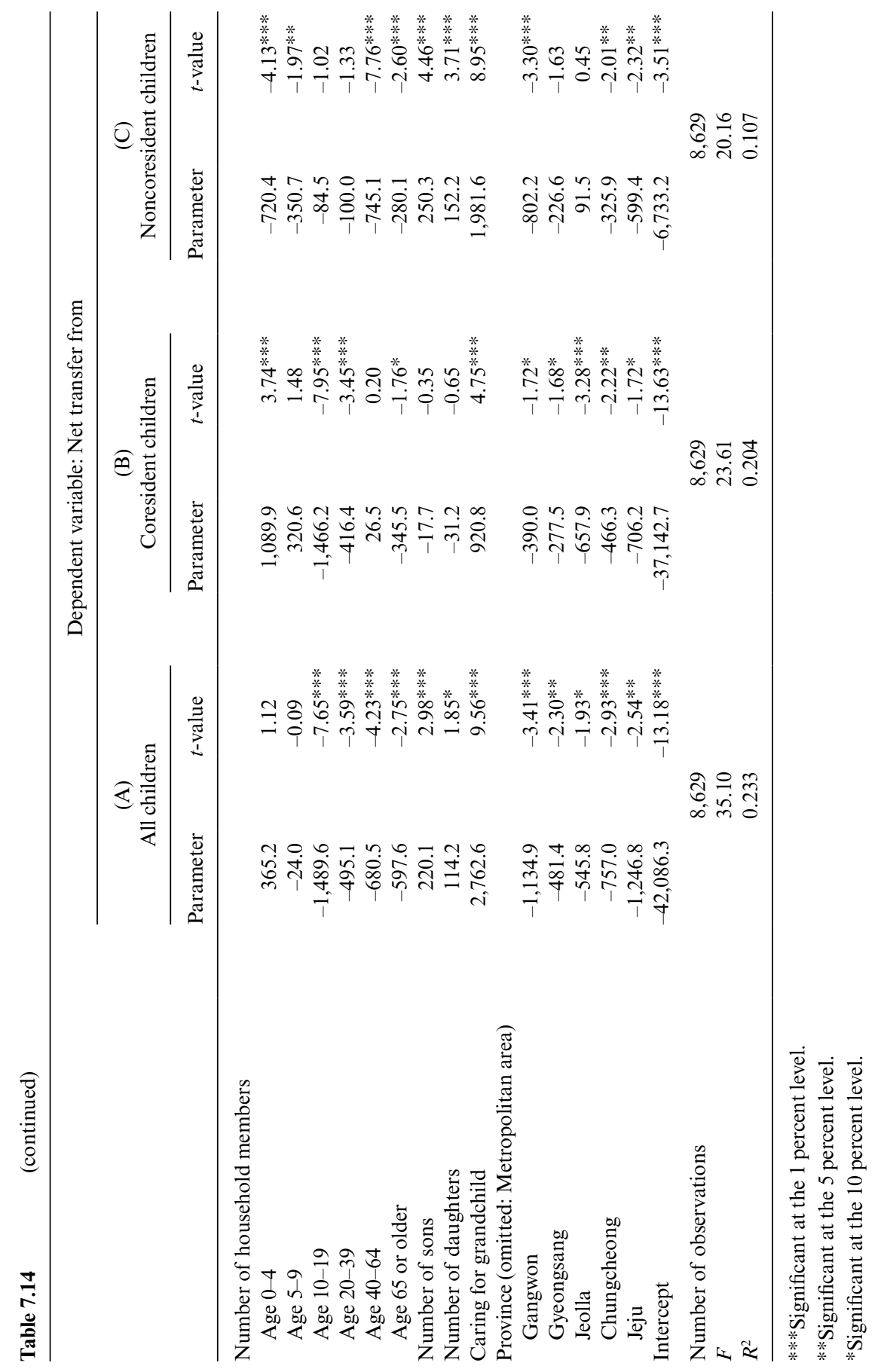


simultaneously in a cross-section model with a parent-child pair being the unit of analysis. But familial transfer behavior can be affected by unobserved family-specific characteristics, which are arguably common across children within a family. Thus, to investigate which child gives more to her or his parents in a family, the best empirical strategy would be a family fixed-effect specification using a sibling sample that consists of multiple parent-child pairs in the family. I confine children to adults (aged nineteen or over) and those who do not live with their parents and are not students at the time of survey. Considering potential differences in the effects of donor's characteristics depending on whether the transfer is regular financial support or occasional irregular transfer, I use three different dependent variables: the amounts of net total/regular/irregular transfer receipts from each adult child in the family.

The main interest is how net transfer receipt is affected by the child's demographic characteristics such as age, birth order, gender, marital status, number of children, and financial status. Since the KLoSA data do not have information on children's income or wealth, I use years of education, home ownership, and work status as proxies for their financial status. In addition, I use variables related to intimacy in the relationship between the respondent and each child. These variables are the child's residential distance from the respondent; frequency of contact in person and by phone, mail, or e-mail; and receipts and gifts of various in-kind transfers. One may have interest in how in-kind transfer variables are related to financial transfers.

Table 7.15 reports regression results from these within-family estimations. To account for the potential relationship of in-kind transfers with net financial transfers, I include dummies for in-kind transfer gift and receipt in specification (a), and then dummies for detailed items of in-kind transfer gift and receipt in specification (b).

Children's demographic variables exhibit some interesting relationships, with net transfers given to their parents. First, the eldest child in the family gives more net regular financial support to the parents by 230,000 won per year. Similarly, the son gives more by 230,000 won per year than the daughter. Thus, both estimates imply that the eldest son makes more transfers than his siblings on a regular base by 460,000 won per year. This reflects an old tradition that the eldest son usually undertakes the responsibility to support his elderly parents and inherits their property (and also the duty of celebrating annual Confucian memorial services for his ancestors) afterwards.

Second, a more educated child gives more total transfer surplus to the parent by 90,000 won per additional one year of education. Looking at regular transfer only, additional transfer surplus from the child's one more year of education is 65,000 won per year. Irregular transfer surplus from child education does not have any statistical significance in every 


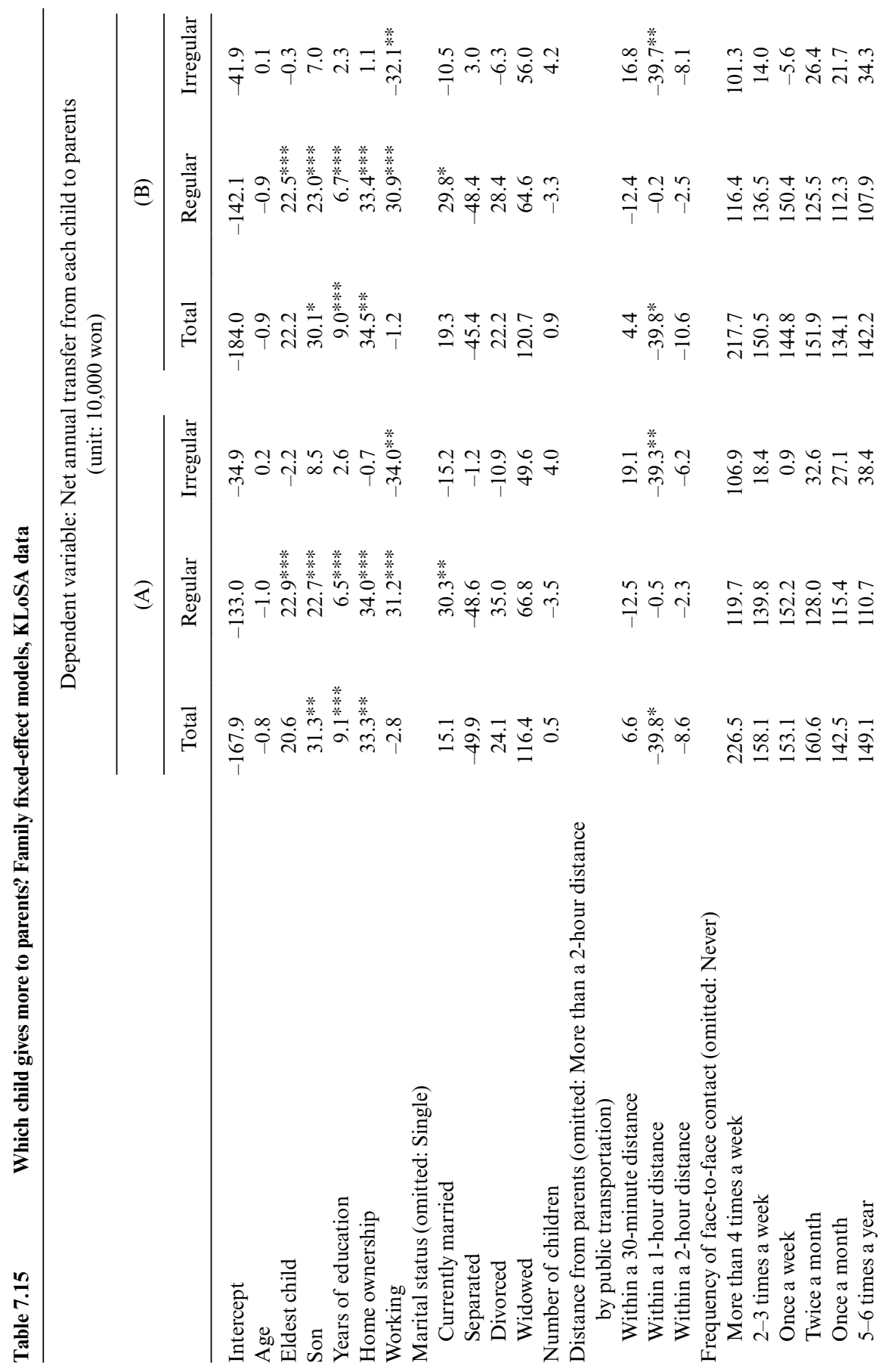




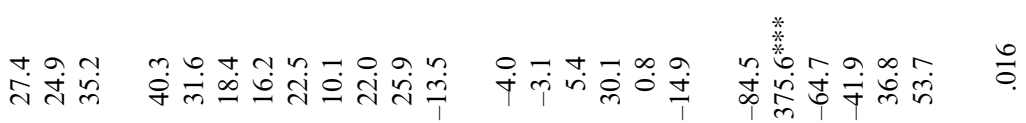

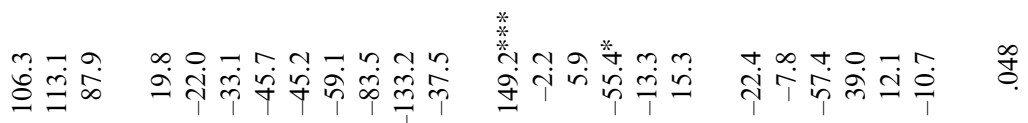

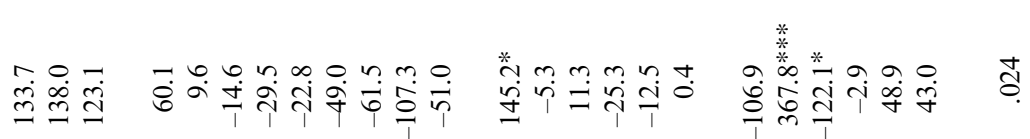

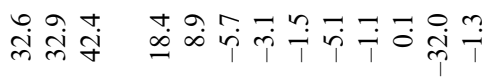

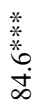

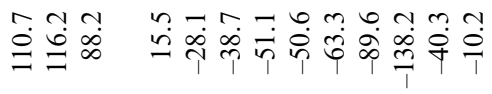

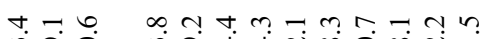

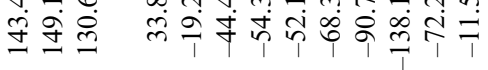
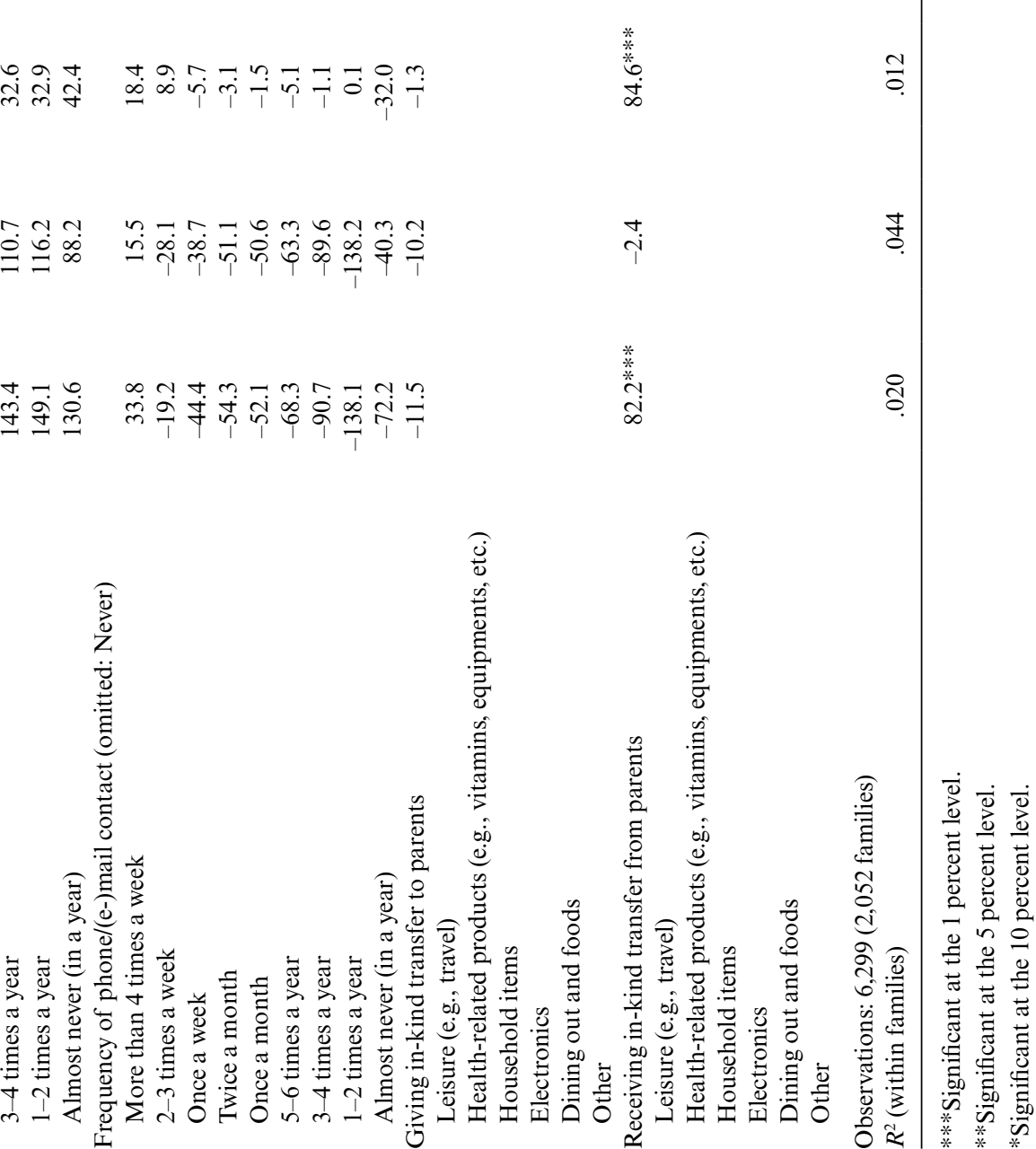
specification. ${ }^{23}$ In addition, when a college graduate dummy is included instead of years of education, total (regular) transfer surplus from the child's college graduation is 430,000 won $(260,000$ won) per year. Therefore, a college-graduate child gives more net regular transfers than her/his siblings who have not graduated from college by only 20,000 won (roughly 20 dollars) per month. If children's education has been funded mainly by their parents, this "repayment" looks too small. ${ }^{24}$ In light of this, child education can hardly be a retirement plan for the parents.

Third, a child who has her or his own home makes a larger amount of regular transfer (by 340,000 won per year) than siblings who do not have home ownership. Since the 2006 KLoSA data have no information on children's income or assets other than home, home ownership can be used as a reliable proxy for the economic standing of the child. This result seems trivial, but consistent with the theory that transfers are increasing in the donor's pretransfer income.

Fourth, when we look at total transfers, the child's work status does not seem to be related with transfer behavior. However, looking at regular transfers and irregular transfers separately, we can find an interesting pattern of transfer behavior by the child's work status. A child who has a job makes more regular transfers by 310,000 won per year than her or his sibling who has no job. But the latter makes more irregular transfers than the former by the similar amount, which leads to roughly the same amount of resultant total transfers regardless of the child's work status.

Fifth, a child who is currently married makes more regular transfers than a child who is still single. A child with other marital status does not show any significant difference compared with an unmarried child.

Sixth, parents seem to have the least financial gain from a child who lives within a one-hour distance (by public transportation) than other children living closer or farther. The frequency of a child's face-to-face contact or phone/mail/e-mail contact with the respondent does not show any significant relationship with transfer behavior. ${ }^{25}$

23. Although not provided in this chapter, the specification that includes the square term of years of education is estimated with statistical significance only for the model of net regular transfer. The estimated quadratic function of net regular transfer is increasing in the years of education higher than 11.5 years. But 83.5 percent of the children in the regression sample have at least twelve years of education, so in most cases net transfers from children are positively correlated with their education levels.

24. According to the Organization for Economic Cooperation and Development's (OECD's) Education at a Glance 2007, annual expenditure per student on public education in Korea as of 2004 was estimated as 4,490 dollars for primary education, 6,761 dollars for secondary education, and 7,068 dollars for tertiary education. Furthermore, it is well-known that Korean parents spend large sums of money on the private tutoring for their children. As of 2007 , average monthly spending per student on private tutoring is estimated by 276 dollars for primary school, 338 dollars for middle school, and 386 dollars for high school (Korea National Statistical Office, February 2008).

25. At the beginning of my estimation, a regression using the entire KLoSA children sample showed that a child who had never contacted the respondent in person made a significantly 


\begin{tabular}{lclr}
\hline Eldest son & $42.4(53.6)$ & \multicolumn{1}{c}{ Other children } & 46.4 \\
\hline Firstborn and only son & 9.8 & Other son & 10.8 \\
Non-firstborn but only son & 5.5 & Daughter with no brother & 6.7 \\
Non-only son but eldest son & 27.2 & Daughter with 1 brother & 15.6 \\
Non-only son but can be eldest son & $(11.2)$ & Daughter with 2 or more brothers & 13.3 \\
\hline
\end{tabular}

Source: Calculated by the author using the $2005 \mathrm{KReIS}$ data.

Note: All numbers are weighted using household weights.

Finally, parents receive a larger amount of net irregular transfer from children whom they gave some in-kind transfers than from other children whom they did not. If this is because parents gave a smaller amount of irregular financial help to the child who received some in-kind transfers, the relationship implies that in-kind transfer and irregular financial transfer are substitutes. Instead, if this is because the child gave a greater amount of irregular financial help to the parents, the relationship implies that children's occasional financial transfers are made in return for the in-kind transfers received from their parents. Specification (b) examines what type of in-kind transfers are related to financial transfers. The results show that a child who provides parents with a leisure gift such as travel gift certificates is probably a regular financial helper to the parents. In addition, a child's occasional financial transfer is made probably in return for a parental gift of healthrelated products.

The KReIS data do not have any information on the respondents' children except the number of sons and daughters. But the KReIS survey contains a useful question for this study, which reads: "Which child is providing the biggest financial help to you with nothing in return?" To this question, the respondent reports the birth order and gender of the child so that we can identify the major financial supporter's birth order and gender. Table 7.16 summarizes the best information that can be drawn from the data. We find again a dominant role of the eldest son in supporting elderly parents. At least 42 percent of KReIS households pinpoint their eldest sons as major financial supporters.

\subsection{Deteriorating Familial Support and Policies for Old-Age Security}

The tradition of familial support for the elderly in Korea is on a decreasing turn due to broadly documented socioeconomic factors such as nuclear fam-

\footnotetext{
larger transfer than other children who had been in some contact. But this result was driven by an extreme outlier who made a huge amount of net transfer $(43,200,000$ won a year), which I have dropped from the sample.
} 
ily, individualism, population aging, and changing preferences for multigenerational coresidence. In this regard, the demand and expectation that the government should expand programs to guarantee the income of the elderly are growing. This section describes changes in familial support mechanism and discusses potential income sources of the elderly.

\subsubsection{Changes in Familial Support Mechanism}

Decreasing Portion of Familial Transfer as Main Source of Elderly Income

Familial transfer has been losing importance as a private safety net for Korean elderly. As shown in table 7.17, the proportion of Korean elderly aged sixty or older who report that their main source of income is financial assistance from their children has decreased from 72 percent in 1980 to 56 percent in 1995, and 31 percent in 2003. Instead, the proportion of public transfers as the main source of income has increased, owing to welfare expansion after the late 1990s financial crisis in Korea. As a result, a quarter of the elderly aged sixty or older was living mainly on public transfers as of 2003. Considering that public transfers tend to crowd out private transfers, private demand for welfare programs for the elderly is likely to increase further.

\section{Changing Patterns of Children's Coresidence with and Support for Elderly Parents}

This study focuses on intergenerational transfer as a pillar of familial support mechanism. But another pillar should be intergenerational coresidence. Coresidence implies sharing of food and utilities as well as housing, so it may be altruistic from the standpoint of the richer member in the family. However, intergenerational coresidence is sometimes demanded by children

Table 7.17 Changing patterns of main source of the elderly (aged sixty or older) income in Korea (\%)

\begin{tabular}{llrrr}
\hline Income source & Items & 1980 & 1995 & 2003 \\
\hline Labor & Wage, own business, etc. & 16.2 & 26.6 & 30.4 \\
Property & Rent, interest, dividend, deposit withdrawal, & & & \\
& $\quad$ private pension, etc. & 5.5 & 9.9 & 9.9 \\
Private transfers & 75.6 & 56.6 & 31.4 \\
& Subtotal & 72.4 & 56.3 & 31.1 \\
& $\quad$ From children & 3.2 & 0.3 & 0.3 \\
Public transfers & From other persons & 2.0 & 6.6 & 25.6 \\
& Subtotal & 0.8 & 2.9 & 10.6 \\
& Public pension, social insurance & 1.2 & 3.7 & 15.0 \\
\hline
\end{tabular}

Sources: Kim (2006, Table 2-13, 58). The 1980 and 1995 figures are from Seok and Kim (2000) who cited Japanese government's cross-country survey, and the 2003 figures are calculated by Kim (2006), using the additional survey for the aged cohort in the 2003 KLIPS data. 
who need parents' help for living. Anyway, relatively high prevalence of coresidence between elderly parents and adult children in Korea is generally interpreted as a structural manifestation of traditional family norms.

Although fewer parents are expecting to live with their adult children these days, some parents are probably curious about which child will live with them in their old age. ${ }^{26}$ Table 7.18 provides an answer to this question. Using KLoSA data, I investigate adult children's characteristics as the determinants of their status of coresidence with their parents. Again, I confine the children sample to those who were aged nineteen or older and were not students at the time of survey. To control for unobserved familial heterogeneity and also to see the results from a parent's point of view, I compare the likelihoods of coresidence with elderly parents between siblings within a family using fixed-effect logit estimation (Chamberlain logit model).

Column (a) reports the likelihood of coresidence is high when the child is the eldest and a son, which reflects a traditional norm of the eldest son's coresidence with his parents. The positive effect of the years of education of a child on the coresidence likelihood implies that more investment in a child's education and resultant higher earning potential of the child would place more responsibility of supporting elderly parents on the child. The positive effect of a child's home ownership and having a job also indicates that elderly parents tend to live with children with better economic standings. The positive correlation of coresidence with the number of children of the child suggests that there is another motivation of coresidence with parents - taking care of grandchildren. The formation of three-generation households has been motivated partly by this instrumental concern of exchanging the adult child's old-age support with the elderly parents' child care service. Looking at marital status, married children are less likely to live with their parents than unmarried children. However, if they get separated, divorced, or widowed, the probability of their coresidence with their parents increases again.

In columns (b) and (c), I examine the effects of home ownership and work status interacted by marital status. Home ownership and employment raise the likelihood of married children's coresidence with their parents, which shows again that the abler children are more likely to support their elderly parents. Unmarried children, however, are more likely to leave their parents if they have a necessary condition for independence-jobs.

In traditional extended families, the eldest sons undertake the most responsibility to support their elderly parents. The regression results in table 7.18 show that there still remains a tendency of the eldest son's supporting elderly parents by intergenerational coresidence as well. However, recent

26. According to a survey of Korean Baby Boomers (born between 1955 and 1963), conducted in 2007,69.7 percent believe that children should leave parental home after marriage (The Korea Economic Daily [Han-Gook-Gyeong-Je-Sin-Moon], June 18, 2007). 


\begin{tabular}{|c|c|c|c|c|c|c|}
\hline & \multicolumn{6}{|c|}{ Dependent variable: Whether living with parents } \\
\hline & \multicolumn{2}{|c|}{ (A) } & \multicolumn{2}{|c|}{ (B) } & \multicolumn{2}{|c|}{ (C) } \\
\hline & Parameter & $z$-value & Parameter & $z$-value & Parameter & $z$-value \\
\hline Age & 0.016 & $1.69^{*}$ & 0.019 & $1.98 * *$ & 0.019 & $2.05^{* *}$ \\
\hline Eldest child & 0.190 & $2.33 * *$ & 0.186 & $2.26 * *$ & 0.177 & $2.16^{* *}$ \\
\hline Son & 1.020 & $12.39 * * *$ & 0.872 & $10.19 * * *$ & 1.200 & $15.82 * * *$ \\
\hline Years of education & 0.066 & $3.55^{* * *}$ & 0.063 & $3.39^{* * *}$ & 0.088 & $4.80^{* * *}$ \\
\hline Number of children & 0.190 & $3.83^{* * *}$ & 0.199 & $3.98 * * *$ & 0.195 & $3.97 * * *$ \\
\hline Home ownership & 0.264 & $2.81 * * *$ & & & & \\
\hline Working & 0.323 & $3.72^{* * *}$ & & & & \\
\hline Married & -3.009 & $-23.02 * * *$ & -3.609 & $-22.24 * * *$ & & \\
\hline Married and own home & & & 0.276 & $2.74 * * *$ & & \\
\hline Married and working & & & 0.762 & $6.35^{* * *}$ & & \\
\hline Separated & -0.712 & $-1.65^{*}$ & -1.843 & $-3.00 * * *$ & 1.149 & $1.84^{*}$ \\
\hline Separated and own home & & & -0.138 & -0.10 & 0.204 & 0.14 \\
\hline Separated and working & & & 2.368 & $2.58 * * *$ & 2.365 & $2.51^{* *}$ \\
\hline Divorced & -0.519 & $-2.55 * *$ & -0.863 & $-2.75 * * *$ & 2.164 & $6.93^{* * *}$ \\
\hline Divorced and own home & & & -0.229 & -0.50 & -0.264 & -0.57 \\
\hline Divorced and working & & & 0.600 & 1.61 & 0.567 & 1.48 \\
\hline Widowed & -1.328 & $-4.77 * * *$ & -1.556 & $-3.89 * * *$ & 1.580 & $4.10^{* * *}$ \\
\hline Widowed and own home & & & -0.369 & -0.73 & -0.448 & -0.87 \\
\hline Widowed and working & & & 0.544 & 1.12 & 0.482 & 0.97 \\
\hline Single & & & & & 3.366 & $19.20 * * *$ \\
\hline Single and own home & & & & & -0.244 & -0.86 \\
\hline Single and working & & & & & -0.529 & $-3.44 * * *$ \\
\hline Number of observations & 7,164 & & 7,164 & & 7,164 & \\
\hline Log likelihood & $-1,631.7$ & & $-1,609.0$ & & $-1,632.1$ & \\
\hline Pseudo $R^{2}$ & 0.343 & & 0.352 & & 0.342 & \\
\hline
\end{tabular}

***Significant at the 1 percent level.

**Significant at the 5 percent level.

*Significant at the 10 percent level.

socioeconomic changes in Korea are raising doubts about the sustainability of the tradition of familial support.

The 2003 KLIPS contains an additional survey for the aged (the KLIPS respondents who are aged fifty or older at the time of survey), in which the respondents were asked who undertook the responsibility of supporting their elderly parents. As shown in table 7.19, 71 percent of aged respondents report that the eldest sons lived with or supported their deceased parents while they were alive (question [a]), whereas only 45 percent report that the eldest sons are currently undertaking the responsibility of supporting their elderly parents (question [b]). Meanwhile, the proportion of the elderly taking care of themselves without children's support has increased from 19 percent to 35 percent. Considering that the average age of the respondents 
(A)

Who lived with or supported your deceased parents while

Coresident or supporter for the elderly parents they were alive? $(\%, n=2,597)$
(B)

Who lives with or supports your elderly parents now? $(\%, n=799)$

Changes (\% point)

\begin{tabular}{lrrr}
\hline Alone by themselves & 18.6 & 34.5 & 15.9 \\
The eldest son/daughter-in-law & 70.6 & 45.2 & -25.4 \\
Other sons/daughters-in-law & 6.5 & 13.8 & 7.2 \\
Daughters/sons-in-law & 2.8 & 4.1 & 1.4 \\
All children together & 1.5 & 2.5 & 1.0
\end{tabular}

Source: The additional survey for the old cohort (aged fifty or older) in the 2003 KLIPS.

whose parents are still alive must be lower than that of the respondents whose parents have died, we can infer that traditional norms of the eldest son's responsibility to support his elderly parents have been deteriorating and that the responsibility has been shifting to the elderly themselves. ${ }^{27}$

\subsubsection{Policies for Old-Age Income Security}

As seen before, Korean elderly have been undertaking more responsibilities for their income security. Do they have adequate means to do that? I briefly describe their incomes and wealth by age and by income quintile to find potential ways to old-age security.

The 2005 KReIS and the 2006 KLoSA have a fairly comprehensive set of data items on the respondent's assets and debts as well as detailed components of annual income. In particular, the availability of household wealth data is good news for researchers given the rarity of official wealth data. ${ }^{28}$ Tables 7.20 and 7.21, respectively, report mean amounts of annual income, assets, and debts by the KReIS and the KLoSA respondents' ages. Table 7.22 reports the same items for the KLoSA respondents aged sixty or older by their income quintiles. When constructing income quintiles, I exclude those

27. Although this study deals with financial aspects of elderly life, emotional difficulties suffered by the lonely elderly also cause serious social problems such as elderly suicide. As of 2004, 4,118 elderly people aged sixty or older committed suicide in Korea; that is, eleven persons a day. The elderly suicide rate has increased four times for a decade in Korea, ranked top among OECD countries. The suicide rate of the elderly living alone is three times higher than that of the average elderly. According to the 2006 elderly statistics reported by Korea National Statistical Office, 18 percent of people aged sixty-five or older live alone without any family members.

28. The 2006 Household Wealth Survey (Korea National Statistical Office, 2007) conducted by Korea National Statistical Office can be regarded as a starting point of collecting wealth data although the raw data of the survey are not available to the public. I reorganize the items of asset and debts in the 2006 KLoSA wealth data following the classification of the 2006 Household Wealth Survey. 


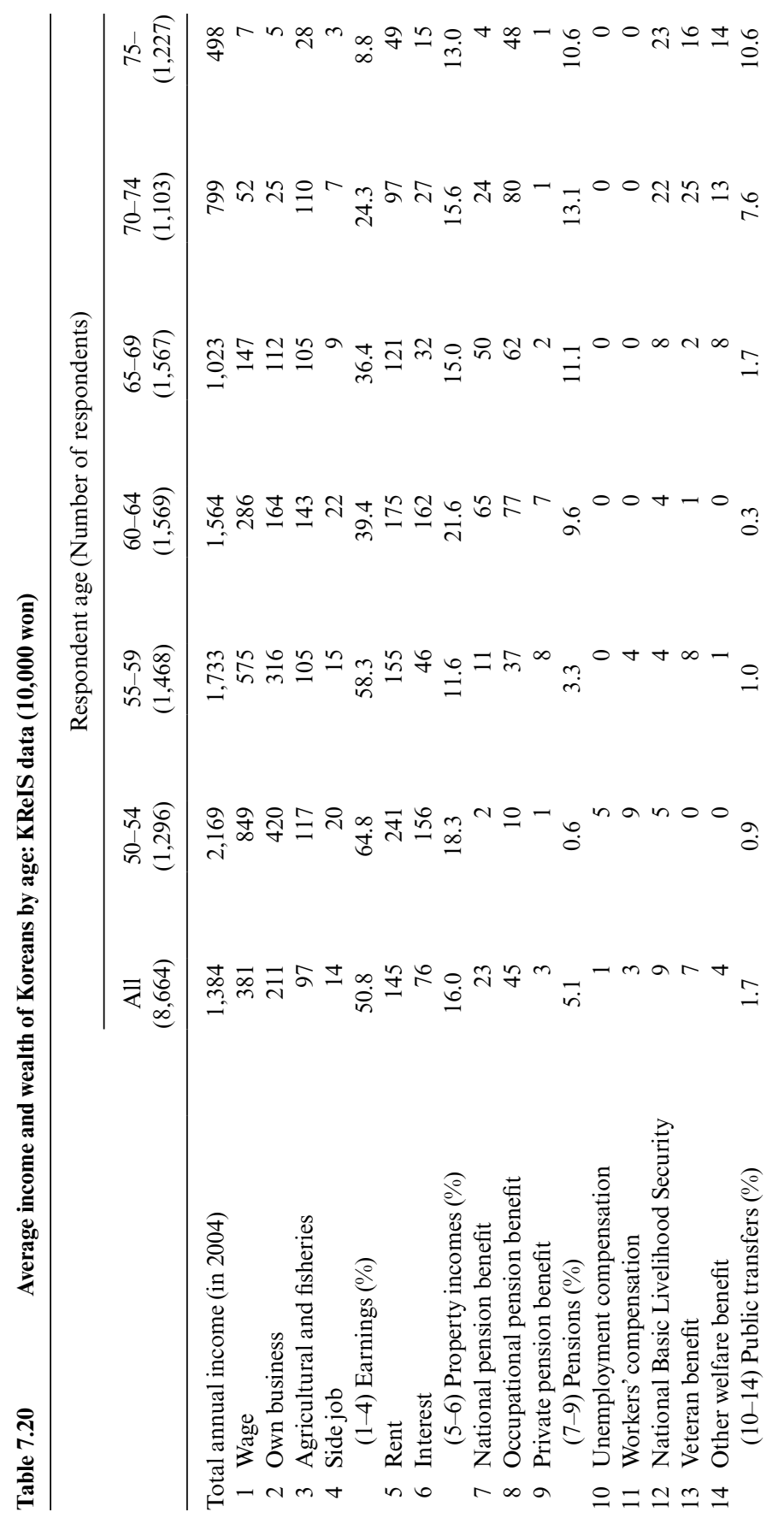




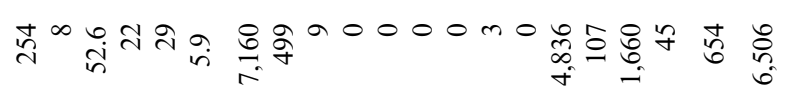

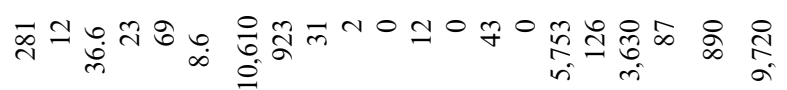

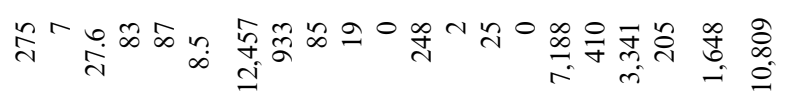

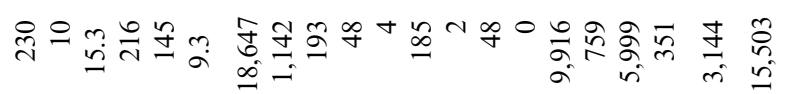

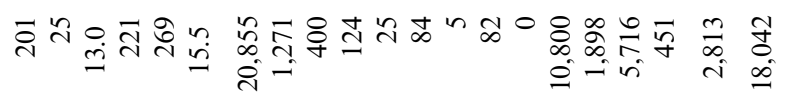

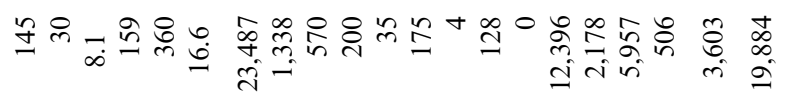

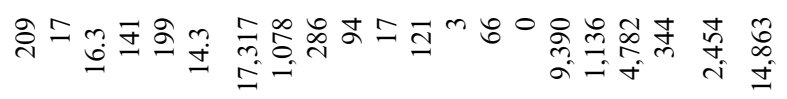

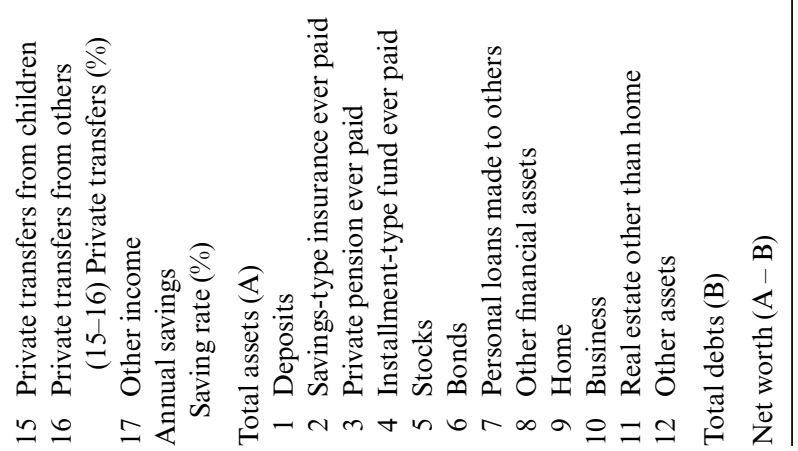




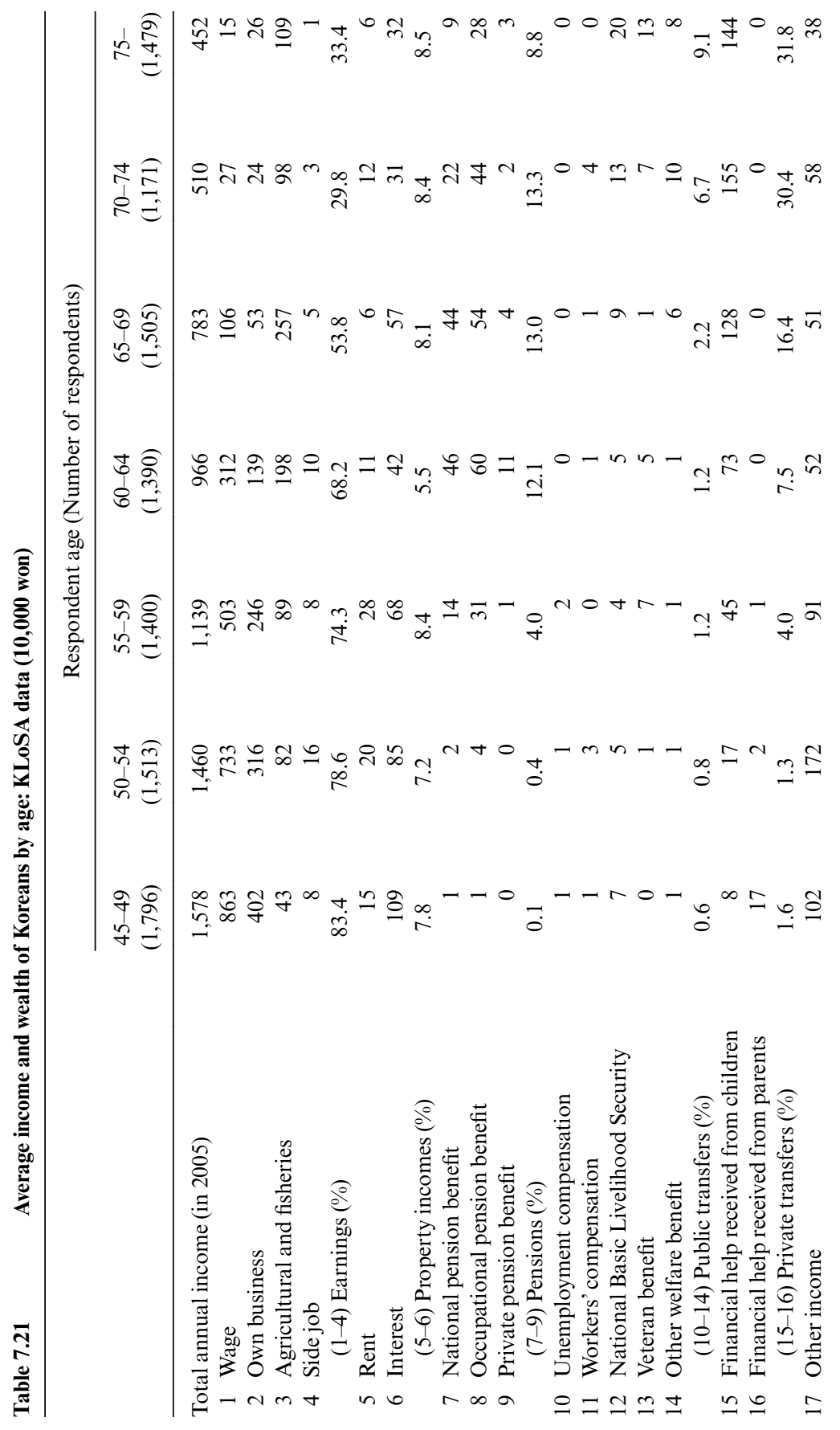




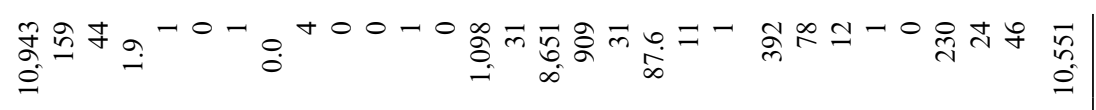

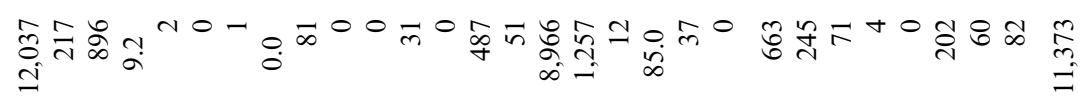

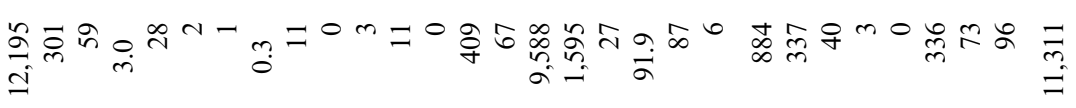

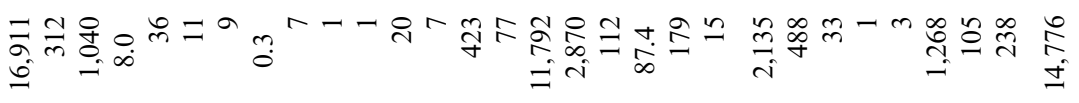

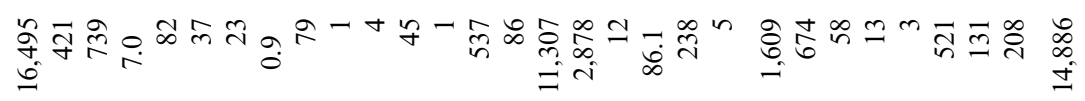

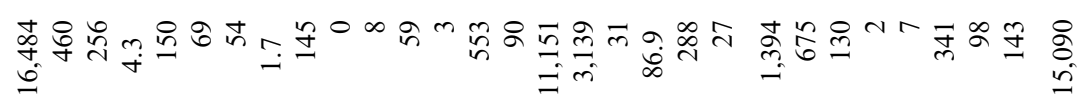

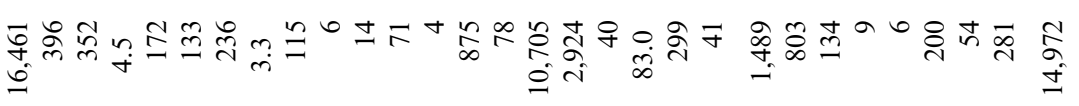

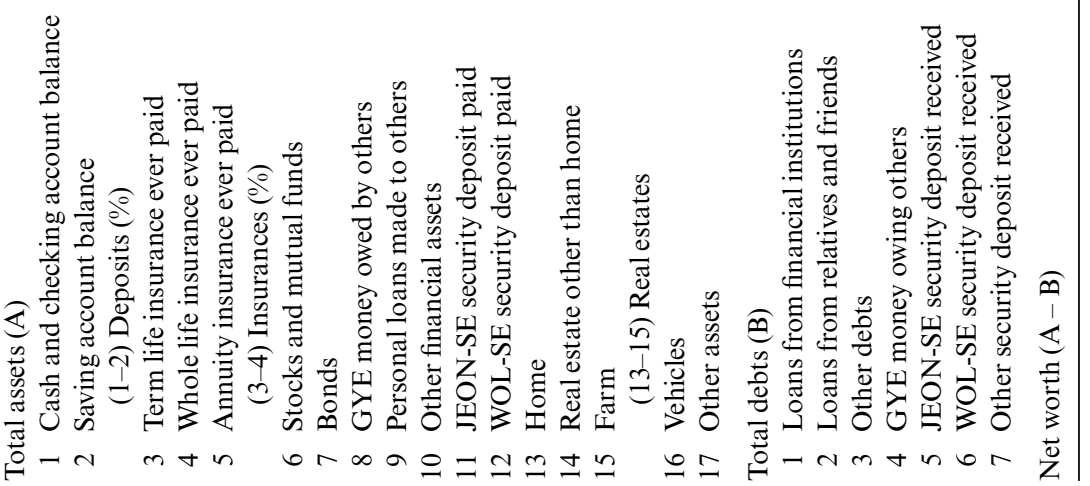




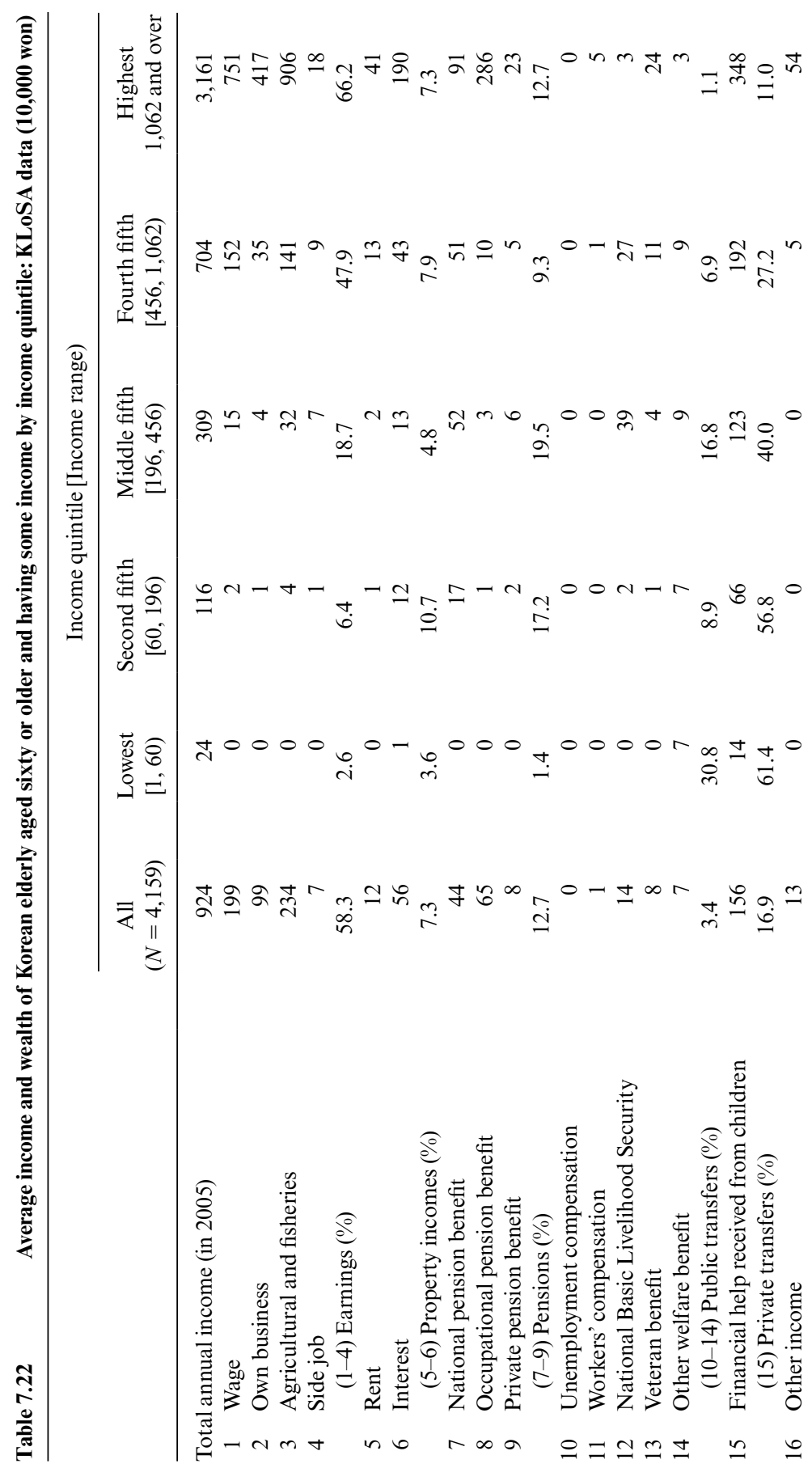




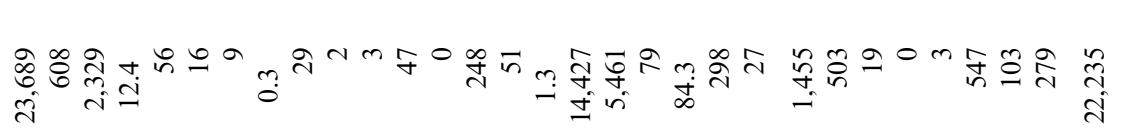

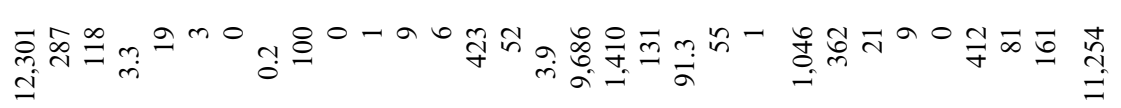

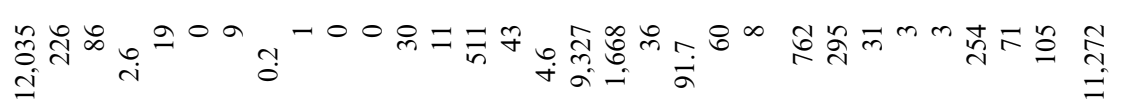

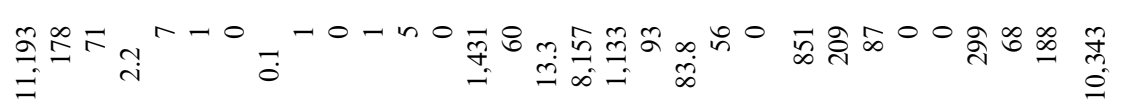

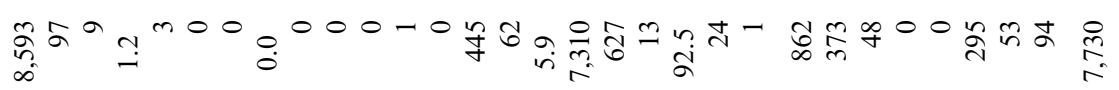

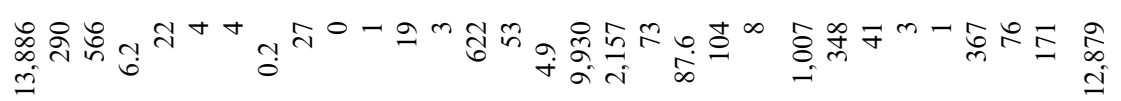

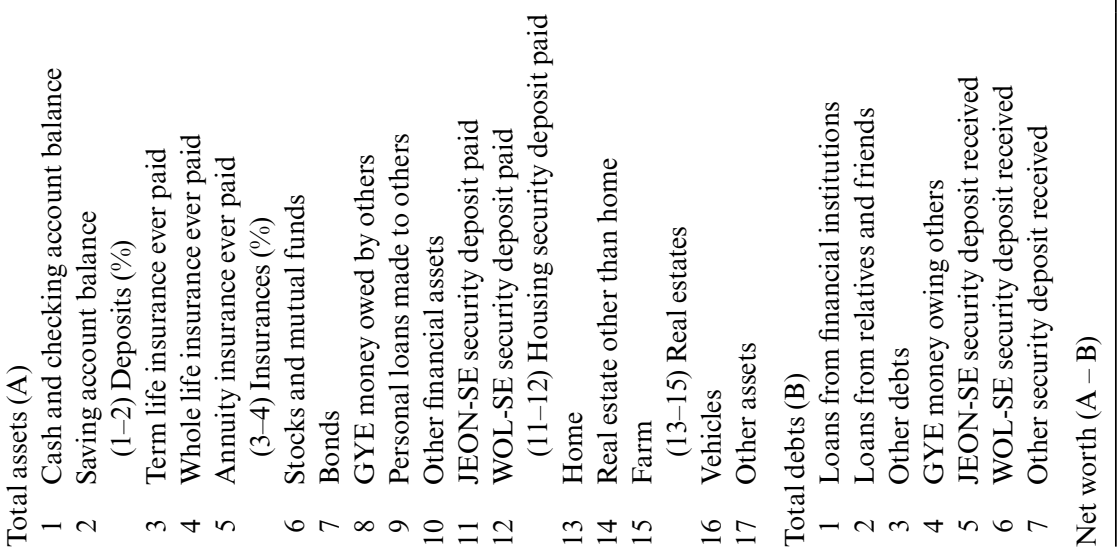


who do not have any income from the sample. Of 4,159 KLoSA respondents aged sixty or older, 25.6 percent are reported to have no income. ${ }^{29}$ Table 7.23 repeats table 7.22 for those aged sixty-five or older. In reading tables $7.21,7.22$, and 7.23, it should be noted that real estate and related security deposits could have been counted redundantly for multiple respondents in the same family, probably a couple, because KLoSA data report assets and debts at the respondent's individual level, not at the household level. In table 7.20, however, assets and debts are reported in the unit of a couple (the KReIS respondent and his or her spouse, if exists).

The $2005 \mathrm{KReIS}$ survey classifies annual income items and private transfer income into the same section, so I add up these variables to construct a variable of total annual income in 2004. Missing and/or refused answers in some income items are imputed with zeros. Using the 2006 KLoSA data, I construct a variable of total annual income in 2005 by summing up income items in the Income section, rent and interest in the Asset section, and private transfers in the Family section. ${ }^{30}$ Table 7.20 and table 7.21 show that total annual income decreases monotonously with the respondent's age. A sharp decline of earnings is not sufficiently compensated by supplementary incomes such as pension benefits and public or private transfers. As a result, the average total annual income of those in their seventies is below half of that of those in their fifties. In the following, I briefly discuss how to make up for the elderly income deficiency by examining each source of income.

\section{Earnings}

Tables 7.17 and 7.19 imply that an increasing number of elderly people now have to make ends meet by themselves. In this regard, one of the most promising income sources would be their jobs. Table 7.22 shows that the main income source of the highest quintile among those aged sixty or older is their employment, own businesses, or farms (66 percent of total annual income). For the highest income quintile among those aged sixty-five or older in table 7.23, the proportion of wage gets lower because of retirement between age sixty and sixty-five, but still 53 percent of their total annual income comes from their jobs, specifically farms. Therefore, job opportunity seems crucial to the income security of the elderly as of yet.

Retirement age has been virtually shortened since the late 1990s financial crisis that has made layoffs easier and pushed early retirement. As a result, the employment of those aged between fifty-five and sixty-four has been declining in Korea while that in major advanced countries was on the uphill.

29. This proportion of the elderly living without income does not necessarily seem to be overestimated. According to the whole population statistics based on the 2007 National Health Insurance data, 30 percent of 4,178,946 elderly households in which at least one person are aged sixty-five or older are reported not to have any income.

30. Of course, private transfer receipts reported in the Family section are not included in the annual income that is used as an explanatory variable in the regression models of table 7.13. 


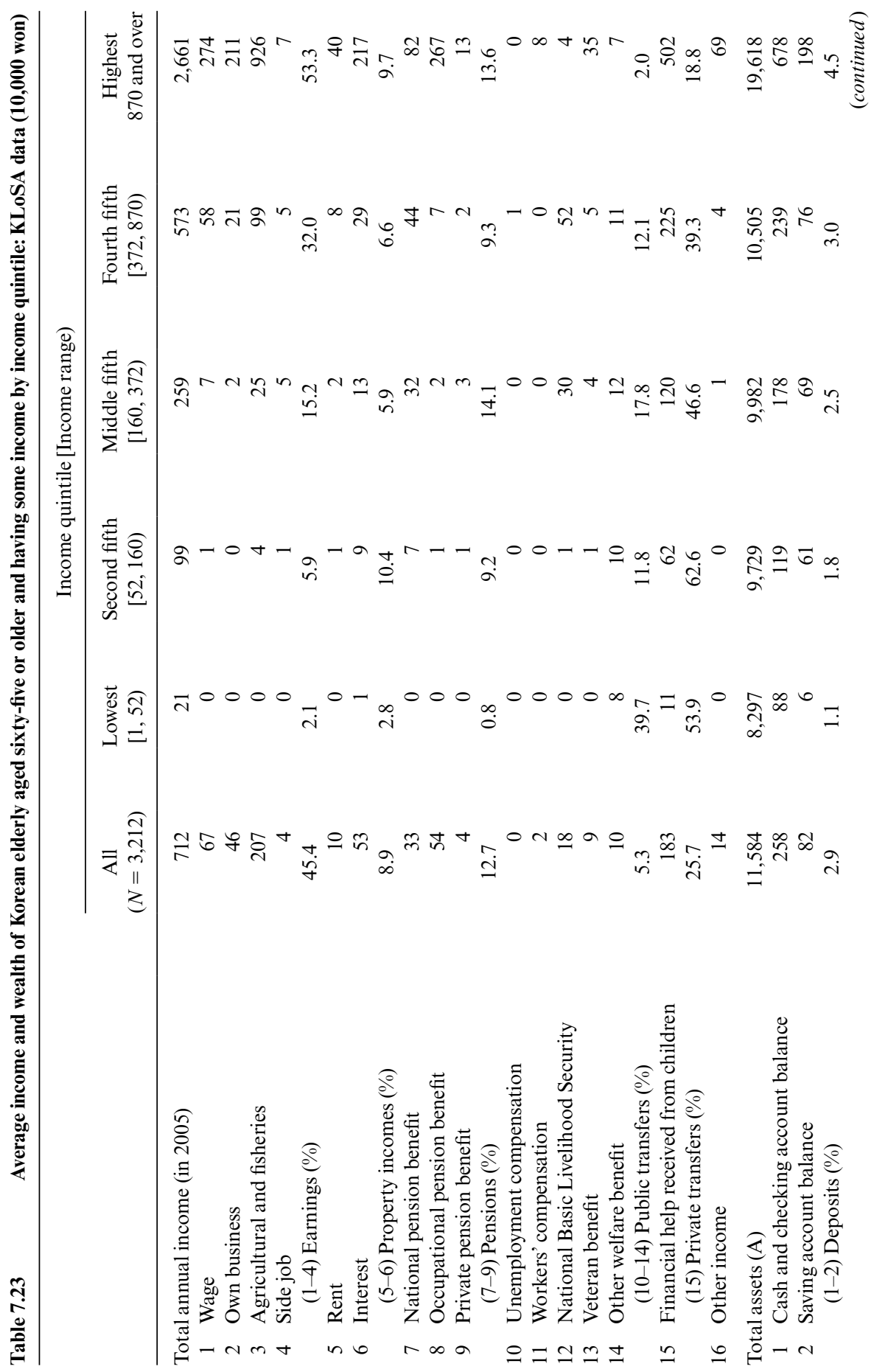




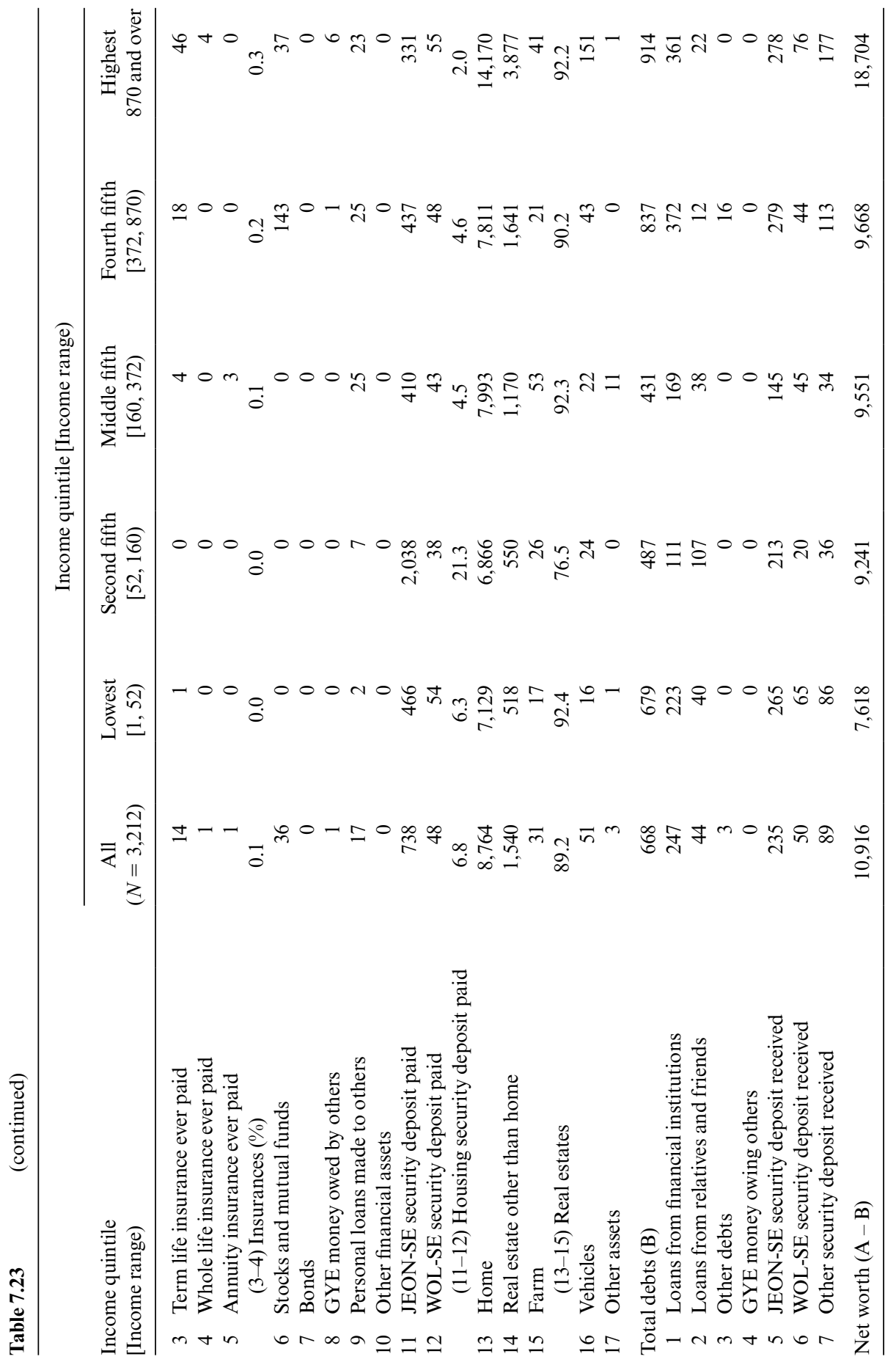


In Korea, people generally exit from their main career at an average age of fifty-four and work for another thirteen to fourteen years at new workplaces with substantially worsened working conditions until they permanently stop working at the age of sixty-eight.

Now to postpone retirement in a rapidly aging society like Korea, systematic efforts would be needed. For example, we may consider a wider adoption of the Wage Peak System to address employers' concern about an increase in labor cost by retaining the aged under seniority-based payment scheme. And we may also consider a deferred pension and annuity system to give employees an incentive to delay their retirement.

Given that Korea's economically active population aged between twentyfive and fifty-four declines from 2009, employment of the aged plays a role not just in elderly income but also for addressing a possible labor shortage. Stereotypical perceptions of employing the elderly, and the extent to which workers invest in their own human capital, are also factors. One option might be to facilitate employers' investment in developing the aged-friendly training programs and strengthen self-motivated capability development by the aged workers. Elderly employment projects could also target more competitive programs by tailoring job opportunities to each elderly individual's need, ability, and willingness to work.

\section{Property Incomes}

As shown in tables 7.20 through 7.23, most properties of Korean elderly are real estates (more than 80 percent of total assets), and the majority of elderly has virtually nothing other than their residential home. In this regard, the Reverse Mortgage Loan was introduced in 2007 to let those who are "house-rich but cash-poor" have regular income by liquidation of their residential home with staying in their home until they die. In addition, even though few elderly have stocks, mutual funds, or bonds right now, the proportion of financial assets in elderly nest eggs will rise as capital markets are rapidly growing. ${ }^{31}$

\section{Pensions}

Public and private pension systems have a relatively short history in Korea compared to advanced western economies. Hence, the coverage and sufficiency of benefits are not yet up to the level of a major source of retirement income as seen in tables 7.20 and 7.21. Compared to the National Pension that started in 1988 and has not yet matured, occupational pensions have longer histories and higher replacement rates. Tables 7.22 and 7.23 show that the beneficiaries of occupational pensions are likely to occupy the highest income quintile among Korean elderly. Occupational pensions, 
however, cover very limited occupations such as public employees, teachers, or soldiers, in spite of requiring substantial inflow of government budget. Moreover, the National Pension system is likely to face fiscal drain in several decades if the current scheme will not be drastically reformed soon. A corporate pension scheme that has been recently introduced is one alternative step toward a multipillar old-age security system based on public-private pension linkage. ${ }^{32}$ However, institutional rearrangements might be needed if private pensions or annuities were to be used as a means of securing retirement income. Tables 7.20 and 7.21 suggest that private pension/annuity (insurance) application of the elderly has been negligible, although those in their forties and fifties now seem to have more interest in that.

\section{Public Transfers}

Elderly households are far more prone to poverty. Using KLIPS data, Cho (2007) finds that as of 2005, 45.6 percent of households in absolute poverty are elderly households. Table 7.15 also suggests that the dependency on public assistance increases with age. Tables 7.22 and 7.23 show that those who do not take up the National Basic Livelihood Security benefits find themselves in the lowest income quintile among the elderly. It is not clear whether they are indeed not eligible for the benefits or they are unfairly excluded from them; however, according to Kim (2006), who uses the 2003 KLIPS data on aged respondents, at least 11.3 percent of elderly households whose heads are aged sixty or older are estimated to have been unfairly excluded from the National Basic Livelihood Security benefits despite living in absolute poverty.

The Basic Old-Age Pension benefits supposedly cover a broader range of Korean elderly aged sixty-five or older-60 percent in 2008 , with the maximum benefit at 84,000 won per month. The growing role of governmental efforts in assisting elderly income may indicate the overall improvement of Korea's social welfare.

\section{Private Transfers}

Financial assistance from adult children still occupies a substantial portion of elderly incomes. Table 7.21 reports that the proportion of familial transfer receipts in the KLoSA respondents' total annual income increases after retirement to reach as much as 30 percent in their seventies. Tables 7.22 and 7.23, however, show that the average amount of children's financial transfers received by the highest income quintile elderly is far larger than that of the lowest income quintile elderly. ${ }^{33}$ For the elderly below the middle

32. To establish a multipillar model of old-age income security in Korea, Moon et al. (2005, 2007) provides policy suggestions focusing on pension reforms and the development of pension systems.

33. Since affluent elderly parents tend to make substantial transfers to their children, their net transfer receipts from their children are probably much smaller than their gross transfer receipts. 
income quintile, the average amount of familial transfer receipts is at most 660,000 won (roughly 600 dollars) a year, despite the fact that familial transfers occupy more than half the total annual income. This surely reflects a positive income correlation between parents and children. But it also shows that the anti-poverty effectiveness of private transfers is limited because they are essentially income redistribution within families.

At least for a while, familial support will play a transient role as a private safety net for the elderly until a comprehensive system for old-age income security will have been full-fledged and stabilized. As shown earlier, however, familial support for the elderly is deteriorating in terms of both financial transfers and coresidence with elderly parents. ${ }^{34}$ Moreover, the expansion of elderly welfare will further decrease the role of families in old-age security. But, as Ogawa and Retherford (1997) point out, government seems unable to reverse the trend of a weakening role of familial support. ${ }^{35}$ Encouraging retirement savings through enhancement of long-term saving incentives and promoting elderly employment might be options if the government does not wish to support a growing elderly population.

\subsection{Conclusion}

This study investigates intergenerational transfers in Korea, focusing on children's financial assistance to their elderly parents. According to KLoSA and KLIPS data, two or three out of five households provided some type of financial support for their aged parents. The average amount of net annual transfers from children is approaching 2 million won after retirement age. Even though it is not always sufficient, financial help from adult children has alleviated income deficiency of Korean elderly.

Among many findings from this study, I select four as key stylized facts. First, the negative effect of the recipient's income (and net worth) on net transfer receipt suggests that altruism is the main motive of familial transfers in Korea. This is consistent with the existing literature that concludes altruism prevails as the motivation of private transfers until public transfer programs are well established (see Cox, Hansen, and Jimenez [2004], for example). The exchange motive, however, also appears to operate in the form of more transfers to the parents who look after their grandchildren.

Second, as the theory predicts, as long as private transfers are made in

34. A survey (conducted by Chosun Ilbo Co. and Mirae Asset Securities Co. in August 2005) of 1,001 Korean adults suggests that the current generation has an asymmetric view about the responsibility of supporting their elders and the expectation of being supported by their children. According to the survey, 47.4 percent feel they should support their elderly parents. But only 26.9 percent expect their children will support them after retirement.

35. On the factors that make Japanese government's efforts to shift some burden of supporting the elderly back to families unsuccessful, Ogawa and Retherford list rapid population ageing, decreases in intergenerational coresidence, increases in women's labor market participation and resultant decreases in available caregivers for impaired elderly, and depreciating values of filial piety. 
a compensatory fashion, they are crowded out by public transfers made in the same fashion. The KLIPS data show that there exists almost a dollarfor-dollar crowding-out of private transfers by public assistance benefits (Kim 2006), and the KLoSA data even suggest that positive expectations about public support also decrease elderly parents' net transfer receipt in the family.

Third, intergenerational transfers in Korean families have been under the influence of traditional norms, specifically Confucian ethics that have institutionalized the eldest son's responsibility of taking care of elderly parents. Therefore, even as of 2005, among other children the eldest son undertakes the heaviest burden of supporting his elderly parents through financial help or coresidence with them.

Fourth, I find that child education can hardly be a retirement plan. A child's additional one year of education compared to his siblings only leads to an additional net transfer of 90,000 won per year for the elderly parents. Therefore, parental spending on children's education can be an investment but cannot be the one for the old-age income security of the parents.

Moreover, familial support mechanism has been deteriorating in Korea. Seven out of ten Korean elderly people lived mainly on transfers from their children in 1980, but the proportion is only three out of ten in 2003. This gap has been filled with expansions of public assistance programs and an increased role of self-support. So the burden of supporting the increasing number of the elderly has shifted from families to government; and within a family, it has shifted from the eldest son to the elderly parents themselves.

In light of these findings and ongoing changes, this study leaves some messages for households and government. For households, it suggests preparation for retirement. In the face of rapid population aging and prevailing individualism, the social norm for supporting the elderly is changing from transfers to self-responsibilities. As such, individuals might have to consider longevity risk as well as keeping a balance between savings for their old age and spending on their children, and investing in their own human capital.

Finding an optimal role in the old-age security is a big challenge to the government coping with rapid population aging due to unprecedented low fertility rates, increasing life expectancy, and cohort effect of the Baby Boomers' imminent retirement. Possible alternatives include making more job opportunities for the elderly, enhancing long-term saving incentives, and pension reforms. In front of an increasing elderly population, political settlements tend to introduce universal welfare that covers most elderly people and generous benefits. However, considering that roughly half of households living in poverty are elderly households, poverty reduction for the elderly may come to the forefront. In addition, before introducing new welfare programs, the existence and magnitude of latent demands for the service and potential crowding-out effect of the program on private sectors should be accounted for and measured in a reasonable way. 


\section{References}

An, C.-B., and S.-H. Jun. 2006. Retirement plans and household saving behaviors. The 7th Conference of Korean Labor and Income Panel Study, February 2, 2006 (in Korean).

Brown, J. R., and S. J. Weisbenner. 2002. Is a bird in hand worth more than a bird in the bush? Intergenerational transfers and savings behavior. NBER Working Paper no. 8753. Cambridge, MA: National Bureau of Economic Research, January.

Cho, Y.-S. 2007. The realities of recent elderly poverty and policy implications. The 8th Conference of Korean Labor and Income Panel Study, February 1, 2007 (in Korean).

Cox, D. 1987. Motives for private income transfers. Journal of Political Economy 95 (3): 508-46.

Cox, D., Z. Eser, and E. Jimenez. 1998. Motives for private transfers over the life cycle. Journal of Development Economics 55 (1): 57-80.

Cox, D., B. E. Hansen, and E. Jimenez. 2004. How responsive are private transfers to income? Evidence from a laissez-faire economy. Journal of Public Economics 88 (9-10): 2193-219.

Cox, D., and G. Jakubson. 1995. The connection between public transfers and private interfamily transfers. Journal of Public Economics 57 (1): 129-67.

Cox, D., and M. Rank. 1992. Inter vivos transfers and intergenerational exchange. Review of Economics and Statistics 74 (2): 305-14.

Dunn, T. A., and J. W. Phillips. 1997. The timing and division of parental transfers to children. Economic Letters 54 (2): 135-37.

Gale, W. G., and J. K. Scholz. 1994. Intergenerational transfers and the accumulation of wealth. Journal of Economic Perspectives 8 (4): 145-60.

Hochguertel, S., and H. Ohlsson. 2000. Compensatory inter vivos gifts. Working Papers in Economics 31, Göteborg University, Sweden.

Hurd, M. D. 1990. Research on the elderly: Economic status, retirement, and consumption and saving. Journal of Economic Literature 28 (2): 565-637.

Jin, J.-M. 1999. An analysis on the relationship between Social Security transfers and private transfers. Social Welfare Studies (Sa-Hoe-Bok-Ji-Yeon-Goo) 13:16799 (in Korean).

Kang, S.-J., and H.-J. Jeon. 2005. A study on the motivation of private transfer income and the crowding-out effect of public transfer income. Public Economics (Gong-Gong-Gyeong-Je) 10 (1): 23-46 (in Korean).

Kim, H. 2006. Population ageing and income transfers: Microeconomic approach. In Population ageing and income transfers, National Research Council for Economics, Humanities and Social Sciences, Joint Research Project Report 06-05-03. Korea Development Institute: 7-70 (in Korean).

Korea National Statistical Office. 2007. The 2006 household wealth survey report. KNSO, March (in Korean).

Korea National Statistical Office. 2008. The 2007 Survey on Private Tutoring Expenditure. KNSO, February (in Korean).

Laferrère, A., and F.-C. Wolff. 2004. Microeconomic models of family transfers. In Handbook of giving, reciprocity and altruism, ed. L.-A. Gerard-Varet, S.-C. Kolm, and J. Mercier Ythier, chapter 12. North Holland: Elsevier.

McGarry, K. 1999. Inter vivos transfers and intended bequests. Journal of Public Economics 73 (3): 321-51.

2000. Testing parental altruism: Implications of a dynamic model. NBER Working Paper no. 7593. Cambridge, MA: National Bureau of Economic Research, March. 
McGarry, K., and R. F. Schoeni. 1995. Transfer behavior in the health and retirement study: Measurement and the redistribution of resources within the family. Journal of Human Resources 30:S184-S226.

1997. Transfer behavior within the family: Results from the asset and health dynamics study. Journals of Gerontology 52B (Special Issue): 82-92.

Moon, Hyungpyo et al. 2005. Population ageing and old-age income security. National Research Council for Economics, Humanities and Social Sciences, Joint Research Project Report 05-10-02, Korea Development Institute (in Korean).

Moon, Hyungpyo et al. 2007. A comprehensive study on constructing an old-age income security system in Korea. National Research Council for Economics, Humanities and Social Sciences, Joint Research Project Report 07-01-01, Korea Development Institute (in Korean).

Ogawa, N., and R. D. Retherford. 1997. Shifting costs of caring for the elderly back to families in Japan: Will it work? Population and Development Review 23 (1): $59-94$.

Organization for Economic Cooperation and Development (OECD) 2007. Education at a glance, 2007: Paris: OECD.

Seok, J.-E., and T.-W. Kim. 2000. The reality of elderly income and policies for the improvement of income security system. Korea Institute for Health and Social Affairs (in Korean).

Shin, H. Y., B. E. Cho, and A. J. Walker. 1997. A comparative study on caregiving and inheritance patterns: Korea vs. U.S.A. Korean Journal of Home Management (Han-Gook-Ga-Jeong-Gwan-Ri-Hak-Hoe-Jee) 15:125-36 (in Korean).

Sung, J.-M. 2006. Private transfers in the Korean labor and income panel study data. Korea Labor Institute, Monthly Labor Review 15:75-83 (in Korean).

Wilhelm, M. O. 1996. Bequest behavior and the effect of heirs' earnings: Testing the altruistic model of bequests. American Economic Review 86 (4): 874-92.

\section{Comment Jiyeun Chang}

Investigating intergenerational transfers is essential in order to understand the economic status and security of the Korean elderly. Previous researches and journalistic articles reported that they highly depend upon transfers from their adult children to live, although it is also known that the proportion of private transfers among old-age income has been rapidly decreasing for the last few decades. However, empirical studies have been insufficient, mostly because we lacked in data. Based on the new panel data, such as the Korean Longitudinal Study of Aging (KLoSA), many empirical studies are to be expected. "Intergenerational Transfers and Old-Age Security in Korea" by Hisam Kim, although it could use only the data of a single year, makes a great contribution in our understanding, with detailed analysis and plenteous implications.

The most important finding of this chapter is about the motivation of

Jiyeun Chang is a research fellow at the Korea Labor Institute and a visiting scholar at the Center for Advanced Social Science Research, New York University. 